\title{
A SIMPLE ANALYTICAL METHOD FOR EVALUATION OF FLEXIBLE ROCKFALL BARRIER PART 2: APPLICATION AND FULL-SCALE TEST
}

\author{
Z.X. Yu ${ }^{1,2}$, Y.K. Qiao ${ }^{1}$, L. Zhao ${ }^{*}$, H. Xu ${ }^{1}$, S.C. Zhao ${ }^{1,2}$ and Y.P. Liu ${ }^{3}$ \\ ${ }^{I}$ School of Civil Engineering, Southwest Jiaotong University, Chengdu, China \\ ${ }^{2}$ National Engineering Laboratory for prevention and control of geological disasters in land transportation, \\ Chengdu, China \\ ${ }^{3}$ Department of Civil and Environmental Engineering, The Hong Kong Polytechnic University, Hung Hom, \\ Kowloon, Hong Kong, China \\ *(Corresponding author: E-mail: zhaolei@my.swjtu.edu.cn)
}

Received: 4 January 2017; Revised: 25 May 2017; Accepted: 5 June 2017

\begin{abstract}
The companion paper proposed an analytical solution for design of flexible rockfall barrier undergoing large deflection. The part one also reported that the elongation of energy dissipating device plays an important role in buffer mechanism of the system. This paper further studies the governing factors on large deflection of flexible barrier system and then establishes a deflection-control-based mechanical model with improved buffer performance. The factors include the matching property between the energy dissipating device and the support rope, the motion interference during sliding along support ropes, overload protection from lateral support ropes. A prototype model with a nominal energy level of $2000 \mathrm{~kJ}$ was designed using the analytical method introduced in part one of the paper. Both full-scale test and numerical simulation were carried out to investigate the response of the prototype model under impact load. The results show that the motion interference and the braking effect during impact test are effectively controlled by the proposed deflection-control-based mechanical model, leading to an optimized design in terms of system buffer performance. Thus, this paper demonstrates the application of the analytical method presented in part one. The full-scale test and numerical simulation prove the validity and accuracy of the proposed method.
\end{abstract}

Keywords: flexible barrier, buffer performance, rockfall, full-scale test, mechanical behavior, deflection control

DOI: $10.18057 /$ IJASC.2018.14.2.2

\section{INTRODUCTION}

As discussed in the companion paper, the buffer performance of flexible rockfall barrier system is characterized by significantly large deflection, as shown in Figure 1. The researches [1-8] show that the large deflection of flexible rockfall barrier systems generally includes three parts: elastic deformation, inelastic deformation, and sliding movements between the components. The energy absorbed due to inelastic deformation is mainly caused by the plastic deformation of energy dissipating devices, accounting for $60-80 \%$ of the total impact energy on the system [7,8]. The buffer mechanism mainly provided by energy dissipators and ring net is essentially the working mechanism of flexible rockfall barrier system. The rational design by controlling the inelastic deformation is the key aspect to ensure the performance objectives of the flexible rockfall barrier system.

The full-scale tests $[3,4,8]$ show that the system buffer performance is mainly depended on two aspects: the first is the mechanical properties such as working force and potential elongation of the energy dissipating device, and the second is the sliding movements between the ropes with energy 
dissipating devices and the support structure, as shown in Figure 1. The poor design on one of them will lead to an invalid buffer mechanism and further cause failure of the system [3, 4]. Qi [8] reported a failure full-scale test due to the broken of support ropes, as the energy dissipating device was failed to trigger due to large activation force required.

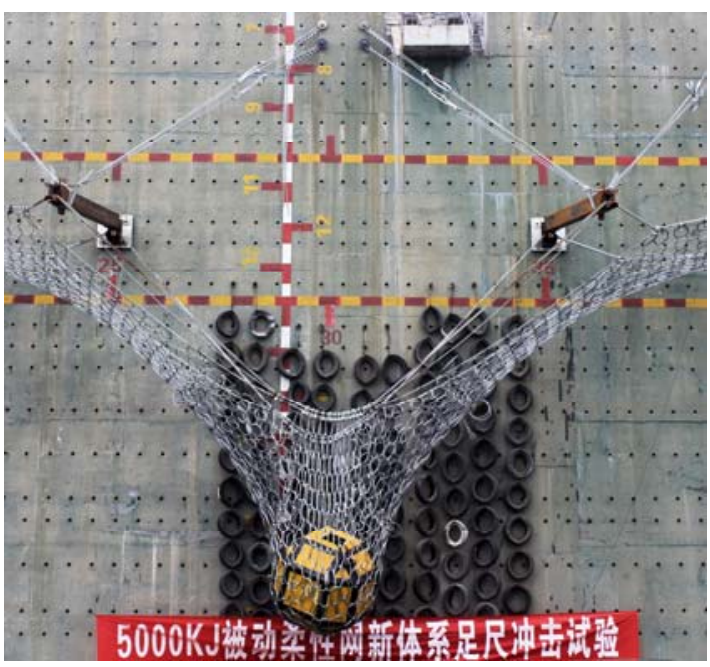

(a) Large deflection of the system

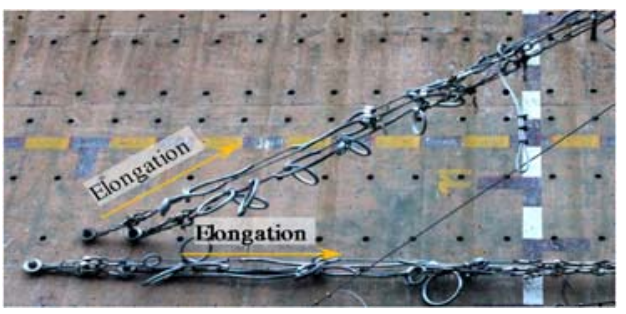

(b) Elongation of energy dissipators

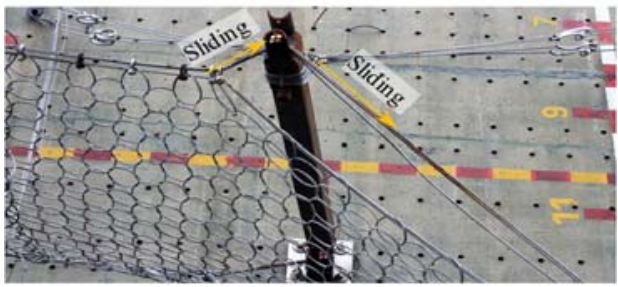

(c) Sliding of support ropes

Figure 1. Full-scale Test of 5000 kJ Flexible Barrier System (Sichuan, China)

Figure 2 shows the unexpected failure modes of the system caused by the motion interference between ropes and other components. As illustrated in Figure 2a, a brake ring on the support rope was stuck by the post head as the rope slid, resulting in a sudden increase of internal force called brake effect in dynamic response of the system. Once the peak force produced by this brake effect grows excessively, the unpredictable damage occurs such as buckling of the steel posts, rupture of the ropes, or puncture of the net as shown in Figure 2b. To the authors' best knowledge, there is few research on the optimized design by improving the buffer mechanism of the flexible barrier system.

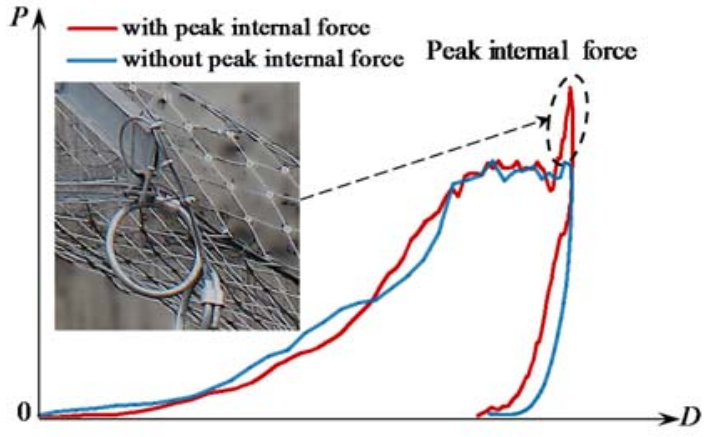

(a) Comparison of P-D curve

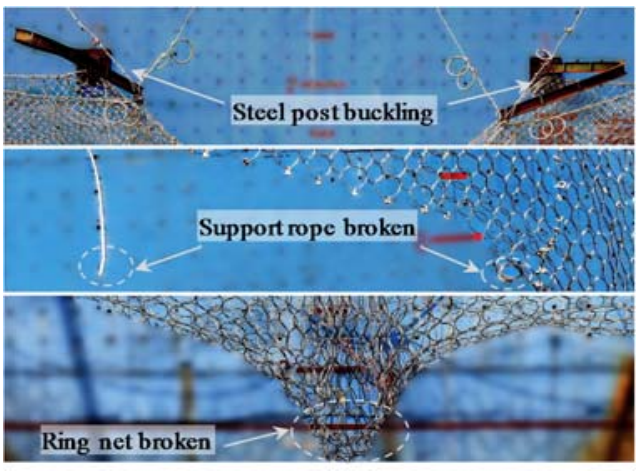

(b) Failure modes

Figure 2. Structural Failure Caused by Brake Effect

Recently, many researchers studied the mechanical performance of flexible barrier system by means of full-scale tests and numerical simulations [1-18]. The advantages and disadvantages of three commonly used structural forms to overcome the motion interference problem in the vicinity 
of steel posts are discussed below.

Peila D et al. [1] conducted full-scale impact tests of flexible rockfall barrier systems under various impact energy levels. Regarding the system with nominal energy level of $400 \mathrm{~kJ}$, the configuration of the steel post, support ropes, and steel wire-ring net is illustrated in Figure 3a. The support ropes will slide through the end of the post when the system is subjected to impact load; while the wire-ring net woven into the ropes will easily jammed by the post, leading to limited development of the system deflection. Their test result showed that the maximum elongation of the system under impact load is only $2.80 \mathrm{~m}$, which indicates that the system is not good enough with poor buffer performance.

Escallon et al. [2] designed a flexible barrier system with nominal energy level of $2000 \mathrm{~kJ}$. In this system, no shackles were used to connect the steel rings (called free ring hereafter) and the support ropes in the region near the steel post to avoid motion interference and stress concentration. They reported that the support ropes are not threaded through wire-rings (or meshes) of the net at the locations close to steel posts. However, several "free" rings located on the top and bottom of the net are attached to the support ropes via connectors, which were seven round clips made of galvanized steel wire with the maximum breaking force of $13.7 \mathrm{kN}$ [2]. All the connectors allow failing in the maximum energy level (MEL) impact test so that a bypassing length can be created as shown in Figure 3b. Through this treatment, the support ropes slid more smoothly under the impact load and the maximum system deflection was increased up to around $9 \mathrm{~m}$. Nevertheless, this method cannot eliminate the interference problem if larger deflection is required since the net will slide along with the ropes simultaneously. Also, the number of "free" rings is limited.

Gottardi et al. [5] carried out a series of full-scale impact tests of flexible barrier systems with nominal energy levels of $500 \mathrm{~kJ}, 1000 \mathrm{~kJ}, 2000 \mathrm{~kJ}, 3000 \mathrm{~kJ}$ and $5000 \mathrm{~kJ}$. For the $500 \mathrm{~kJ}$ and 1000 $\mathrm{kJ}$ systems, the arrangement in the vicinity of the post is the same as that illustrated in Figure 3a. For the systems with higher nominal energy levels $(2000-5000 \mathrm{~kJ})$, the bypassing length is created by adding a transitional rope as shown in Figure 3c, performing the similar mechanism to that implemented by Escallon et al. [2]. However, a sudden brake of sliding motion of support ropes possibly occurs when the connecting joint between the support rope and the transitional rope (point A) moves to the position of the post (point B). Thus, sufficient length for the transitional rope should be reserved when the system is expected a large deflection. The more length for transitional rope means less length for connecting the ring net, resulting in stress concentration in both the support ropes and the net and consequently weakening the protection ability of the system.

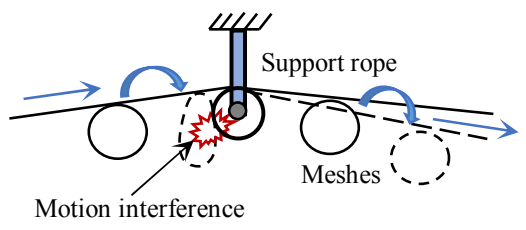

(a) Method 1

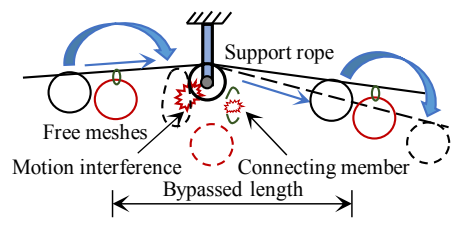

(b) Method 2

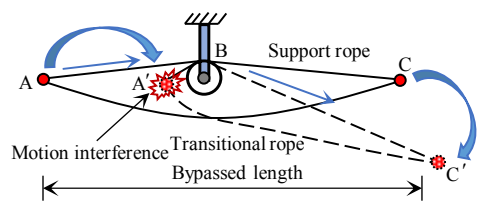

(c) Method 3

Figure 3. Three Typical Configurations Solving Motion Interference Problem

The above typical configurations from the literature cannot completely solve the motion interference problem in the system involving the large deflection, especially under the extreme loading conditions. Hence, the improvement on buffer performance of flexible barrier system is limited. 
This paper aims to improve the system by controlling the large deflection based on the key influence factors. The ratio of the activation force of energy dissipating devices energy to the breaking force of support rope should be designed in a range to ensure their functionality. An improved configuration form for smooth sliding of support ropes was also presented, and the corresponding mechanical model was established. A prototype model of flexible rockfall barrier system with nominal energy level of $2000 \mathrm{~kJ}$ was designed based on the analytical solution proposed in the companion paper. Both full-scale impact test and numerical simulation were carried out to investigate the system response under impact load. Furthermore, eight numerical models with different force-displacement relationships of the energy dissipating devices on support ropes were built to investigate their influence on the controlling of large deflection of the system, which provides a case study for system design.

\section{BUFFER MECHANISM AND DEFLECTION CONTROL}

The layout of support ropes in a typical flexible rockfall barrier system is shown in Figure 4, including the upper and lower support ropes, as well as the lateral support ropes. As mentioned above, a good buffer mechanism is determined by full traveling distance of the energy dissipating devices and the sliding without any stuck of the support rope at the ends of the steel post. It is affected by many factors, such as the ratio of tensile force in the rope to activation force of the energy dissipating device, the configuration of the post end, and the motion interference between components, etc. Thus, the matching design of mechanical properties between components and the optimization design on structural arrangement is of importance for improving the buffer performance of the system.

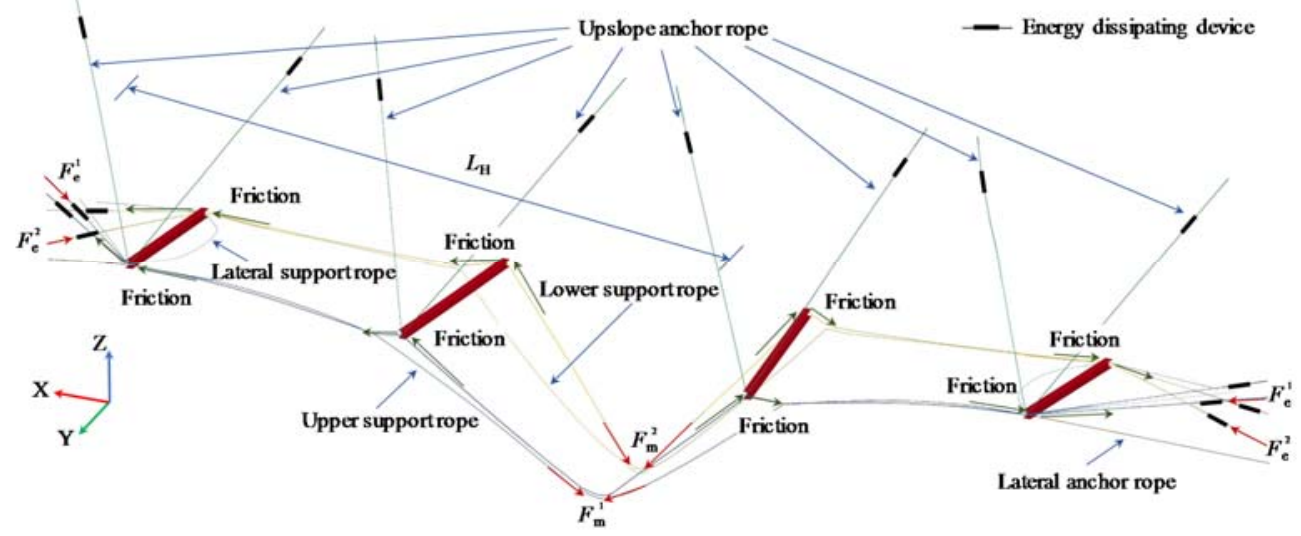

Figure 4. Layout of Support Ropes in Typical Flexible Rockfall Barrier System

\subsection{Matching Design of Energy Dissipating Device and Support Rope}

The performance of the energy dissipating device is depended on the working tension forces $\left(P_{\mathrm{a}}\right.$ and $\left.P_{\mathrm{b}}\right)$ and the elongation $(\delta)$. The traction force of the support rope determines whether the energy dissipating device can be activated and work properly. In a typical flexible rockfall barrier system, in order to avoid that the energy dissipating device is interfered by other components during working, it is often connected to the anchorage points of support rope, as shown in Figure 4. Under the impact of rockfall, the support rope in the impact area firstly generates the tension, which will be transferred to two ends of the rope longitudinally. Due to the friction effect of the post-end bearing and the restraining effect of the ring net on the support rope, when the tension is transmitted to the anchorage point on both sides, the internal force of the rope will be certainly 
reduced. The relationship between the internal force $F_{\mathrm{e}}$ of the rope at anchorage and the internal force $F_{\mathrm{m}}^{i}$ of the rope at the impact zone is shown in Eq. 1a, in which the transfer coefficient $\eta_{i}$ is affected by the traveling distance of the tension and the friction effect along the transmission path. If the tension is largely reduced, the force $F_{\mathrm{e}}$ may be less than the activation force $P_{\mathrm{a}}$ of the energy dissipator. In such case, energy dissipator will stop working, and as a result the system buffer performance will be significantly weakened. Being aware of this, it is necessary to properly design the relationship between $P_{\mathrm{a}}$ and $F_{\mathrm{e}}^{i}$. In reality, $F_{\mathrm{e}}$ is unknown and therefore the ratio $\left(\lambda_{i}\right)$ of the $P_{\mathrm{a}}$ to the breaking force of support rope $\left(F_{\mathrm{u}}^{i}\right)$ is proposed in Eq. $1 \mathrm{~b}$ to establish the relationship for practical application.

$$
\begin{aligned}
& F_{e}^{i}=\eta_{i} F_{m}^{i}(i=1,2) \\
& \lambda_{i}=P_{a}^{i} / F_{u}^{i}(i=1,2)
\end{aligned}
$$

Noted that $i$ equals to 1 and 2 for the upper and lower support ropes, respectively.

In this paper, the numerical simulation of flexible rockfall barrier model with the energy level of 500-5000 kJ under MEL state was carried out to study the attenuation relationship between the forces $F_{\mathrm{e}}^{i}$ and $F_{\mathrm{m}}$. The configuration parameters of the model are referred to GEOBRUGG [19]. The program LS-DYNA [20] was adopted for numerical simulation and the detailed modeling method was referred to the literature [3, 4, 21]. All the numerical simulation models with three functional modules are impacted vertically at the central point of the middle module. The friction coefficient between the support rope and the end of steel post is taken as 0.15 [2]. Table 1 shows the tension forces on the ropes. $L_{\mathrm{H}}$ is the distance between the impact point and the location of energy dissipating device, which is the traveling distance of the tension, as shown in Figure 4.

As shown in Table 1, $\eta_{i}$ varied considerably in different models. With the increase of traveling distance and energy level, $\eta_{i}$ tended to attenuate. For the energy level is $5000 \mathrm{~kJ}$, the $\eta_{i}$ is reduced to 0.57. It means that when the tension transferred from the impact area to the anchorages of support ropes, the reduction is more than $40 \%$, indicating inefficient usage of steel rope. At the same time, excessive reduction of tensile force would make the energy dissipating device out of work and consequently induce large impact force on the system. For safety design of steel rope and anchorage, $P_{\mathrm{a}}$ should be lower than $F_{\mathrm{e}}$. In a word, the energy dissipating device should be properly designed with compatibility of steel rope considering friction effect. For example, Castanon-Jano L [22] suggests that $P_{\text {a }}$ should be less than $50 \%$ of $F_{\text {u. }}^{i}$.

\begin{tabular}{|c|c|c|c|c|c|c|c|c|c|c|c|c|c|}
\hline \multirow{2}{*}{$\begin{array}{c}\text { Energy } \\
\text { levels } \\
(\mathrm{kJ}) \\
\end{array}$} & \multicolumn{6}{|c|}{ Upper support rope } & \multicolumn{6}{|c|}{ Lower support rope } & \multirow[b]{2}{*}{$\begin{array}{c}L_{\mathrm{H}} \\
(\mathrm{m}) \\
\end{array}$} \\
\hline & $\begin{array}{c}F_{\mathrm{m}}^{1} \\
(\mathrm{kN})\end{array}$ & $\begin{array}{c}F_{\mathrm{e}}^{1} \\
(\mathrm{kN})\end{array}$ & $\begin{array}{c}F_{u}^{1} \\
(\mathrm{kN})\end{array}$ & $\begin{array}{c}P_{a}^{1} \\
(\mathrm{kN})\end{array}$ & $\eta_{1}$ & $\lambda_{1}$ & $\begin{array}{c}F_{\mathrm{m}}^{2} \\
(\mathrm{kN})\end{array}$ & $\begin{array}{c}F_{\mathrm{e}}^{2} \\
(\mathrm{kN})\end{array}$ & $\begin{array}{c}F_{u}^{2} \\
(\mathrm{kN})\end{array}$ & $\begin{array}{c}P_{a}^{2} \\
(\mathrm{kN})\end{array}$ & $\eta_{2}$ & $\lambda_{2}$ & \\
\hline 500 & 149 & 126 & 304 & 50 & 0.85 & 0.16 & 158 & 139 & 304 & 50 & 0.88 & 0.16 & 18.25 \\
\hline 1000 & 159 & 117 & 504 & 50 & 0.74 & 0.10 & 157 & 104 & 504 & 50 & 0.71 & 0.10 & 18.25 \\
\hline 2000 & 161 & 132 & 608 & 100 & 0.82 & 0.16 & 335 & 274 & 608 & 100 & 0.82 & 0.16 & 18.25 \\
\hline 3000 & 231 & 146 & 912 & 100 & 0.63 & 0.11 & 318 & 175 & 912 & 100 & 0.55 & 0.11 & 22.50 \\
\hline
\end{tabular}

Table 1. Tension Forces on Support Ropes 


\begin{tabular}{llllllllllllll}
5000 & 496 & 285 & 1216 & 200 & 0.57 & 0.16 & 493 & 292 & 1216 & 200 & 0.59 & 0.16 & 22.50 \\
\hline 2.2 & An Improved Configuration for Support Ropes
\end{tabular}

\subsubsection{Longitudinal Support Ropes}

As discussed in previous section, the improper connection details and structural arrangement may cause the motion interference and further the unexpected damage. In this paper, an improved configuration is proposed for both upper and lower support. The proposed details are presented as follows.

The longitudinal support rope is replaced by a primary support rope and a secondary support rope which are parallel to each other. The wire-ring net is woven through the secondary support rope, which is connected with the primary support rope by shackles. The primary support rope is supported by the ends of posts. The secondary support rope bypasses the ends of posts at the middle functional modules and is only supported by the ends of the edge posts, as shown in Figure 5a. Apparently, the tensile force in the primary support rope increases along with the secondary support rope owing to the connection of the shackles, such that the energy dissipating device mounted on both of them can be activated. It should be pointed out that the angle between the primary and secondary support ropes increases due to the constraints from steel post. This restricts the shackles and wire-ring net to slide towards the post ends. This effect becomes more significant with the increase of the angle $\theta$, as illustrated in Figure $5 \mathrm{~b}$. When the system reaches the maximum deflection, the angle $\theta$ also reaches the maximum value, approaching to $180^{\circ}$ in some cases. The motion interference between support ropes, wire-ring net and post ends can be effectively avoided by using primary and secondary support ropes, seen in Figure 5c.

In the proposed approach, the increment of the angle $\theta$ is in a gradual way instead of a sudden change. Besides, the impact force is shared by the primary and secondary support ropes simultaneously and as a result, the risk of overloading on a single support rope as used in the previous systems can be reduced. Moreover, the secondary support rope can mount an additional energy dissipating device to absorb more impact energy. Thus, under the same energy level, the proposed method will lead to a more efficient system regarding better buffer mechanism and consequently the larger deflection. Nowadays, the high strength steel ropes have been extensively used in many kinds of structures, lowering down the cost of this material. One more ropes used in the proposed system only slightly influence the total cost.

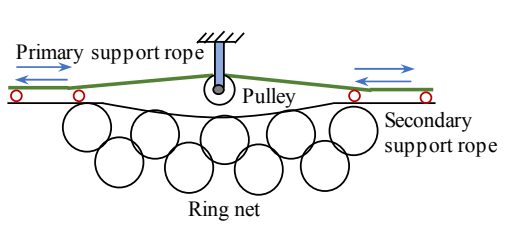

(a) Initial state

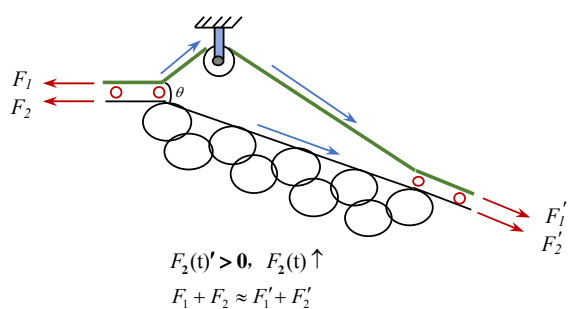

(b) Intermediate state

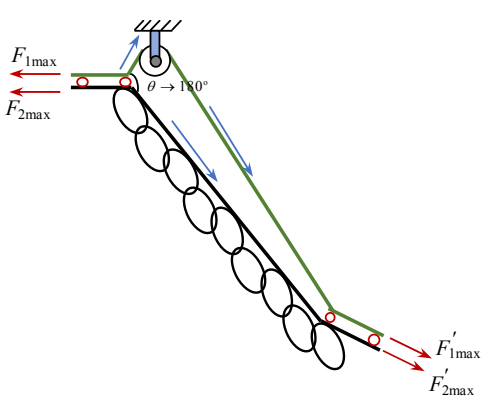

(c) Limit state

Figure 5. Working States of the Proposed Structural Form 
At the mid-span, the primary support rope and the secondary support rope are connected by shackles. They can relatively slide in longitudinal direction as the friction force is small. In the normal direction, the ropes cannot separate freely due to the shackles. This relative sliding movement is extremely beneficial to the restricted effect as mentioned above. The independent movement is essentially a good self-adaptive ability of the system, causing the efficient use of the material as the internal force in the rope tends to be more uniform.

\subsubsection{Lateral Support Ropes}

As the impact location of the system is unknown in the actual case, the wire-ring net is not directly connected to the edge post so that no additional bending moment will be induced on it if the end span is hit by rockfalls. In previous studies $[2,5]$, the lateral support ropes were set as a loop to wrap around the top and bottom ends of the edge post, providing longitudinal restraint for the wire-ring net. The edge posts directly resist the lateral loads from the lateral support ropes. To reduce this unfavorable effect, this paper introduces an improved arrangement form for the lateral support rope, seen in Figure 6. The lateral support rope goes through two ends of the edge post, and then extends to the lateral anchorages in the ground rather than ends as a loop. Since tensile force in the lateral rope is directly transferred to the foundation, the extra force on the edge post will be significantly reduced. Besides, more energy dissipating devices can be added to the lateral support rope to archive larger system deflection and at the same time, provide overload protection for the lateral support rope and the edge post.

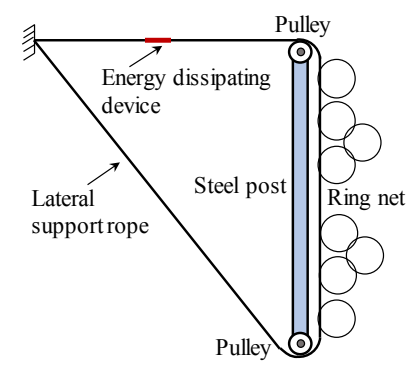

(a) Initial state

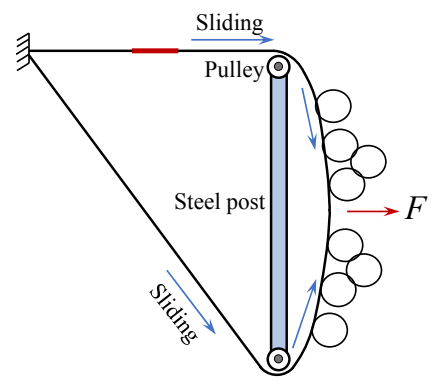

(b) Intermediate state

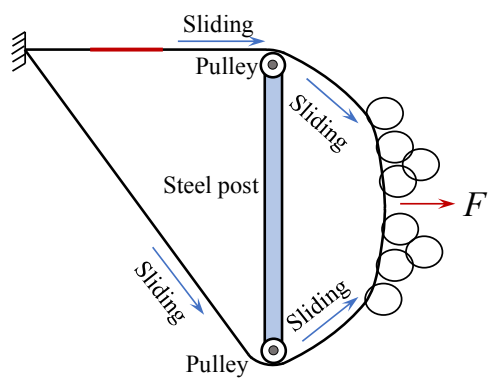

(c) Limit state

Figure 6. Sliding Control of Lateral Support Rope

\subsection{Mechanical Model and Prototype Model of the System}

In this paper, a mechanical model of the flexible barrier based on the improved arrangement of the support ropes is established, as shown in Figure 7. The model is composed of spring-damper elements, cable elements, pulley elements and sliding-spring elements. The stiffness $k_{\mathrm{d}}$ and damping $C$ of the spring-damper element can be determined by the properties of the energy dissipating device. The cable element is for modeling of the steel wire rope in the flexible rockfall barrier system, and its characteristic is determined by the actual properties of steel wire rope. The pulley element represents the sliding constraint of the support rope at the post ends, and its sliding ability depends on the friction coefficient $\mu$. The sliding-spring element represents the ring of wire-ring net, whose spring stiffness $k_{\mathrm{n}}$ and the displacement of sliding $d$ can be determined by the puncturing test of the net. For the net complied with given specification, the parameters $k_{\mathrm{n}}$ and $d$ are constant. 


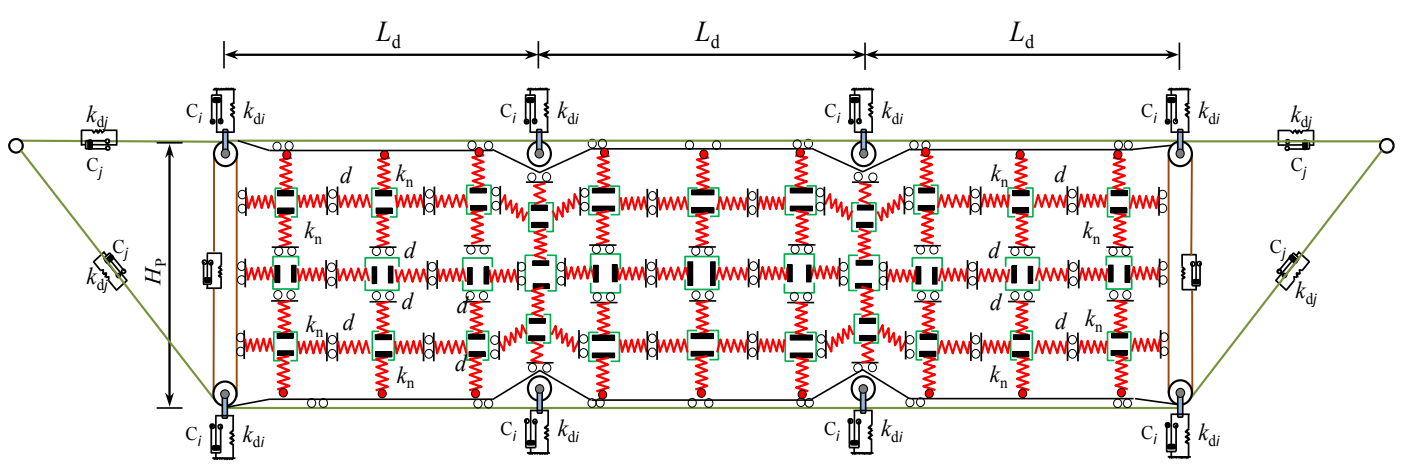

Figure 7. Mechanical Model of the Flexible Barrier System

Accordingly, the prototype model of the proposed flexible rockfall barrier system as shown in Figure 8 is designed to demonstrate the efficiency of the proposed arrangement and analytical method. The system includes steel posts, ring nets, upper and lower primary support ropes, upper and lower secondary support ropes, lateral support ropes, upslope anchor ropes and lateral anchor ropes. The energy dissipating devices are mounted on the extended sections of the primary support ropes, the secondary support ropes and the lateral support ropes. The type, number and arrangement of energy dissipating devices can be determined according to the requirement of protective performance, such as the nominal energy level and the maximum deflection. This system realizes smooth sliding of the support rope and controls the buffer performance by adjusting type, number and arrangement of the energy dissipating devices. Additionally, in order to further increase the buffer performance of system, middle secondary ropes, which are woven through the wire-ring net and anchored to the ground out of the edge posts, can be added between the upper and lower support ropes. The middle secondary ropes are also supported on the steel edge posts, so that they could slide along the steel edge posts. The energy dissipating devices can also be mounted on the middle secondary ropes like other longitudinal support ropes.

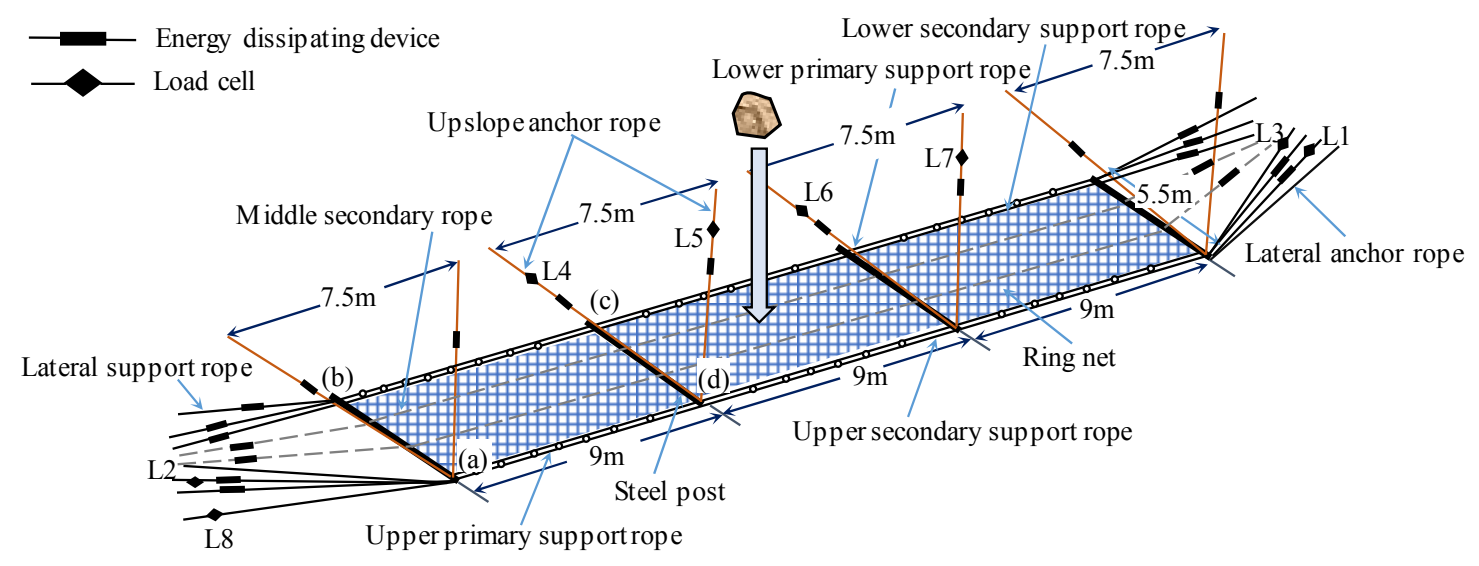

Figure 8. Prototype Model of the Proposed System

\section{FULL-SCALE TEST AND NUMERICAL SIMULATION}

\subsection{Full-scale Test Model}


In order to verify the reliability of the proposed system and to further reveal its mechanical behavior under impact load, an experimental prototype model of the flexible barrier system with nominal energy level of $2000 \mathrm{~kJ}$ was preliminarily designed according to the analytical solution presented in the companion paper. Figure 9 shows the flowchart of the design procedure, in which the final criterion is depended on whether the maximum deflection is within the design limit or not.

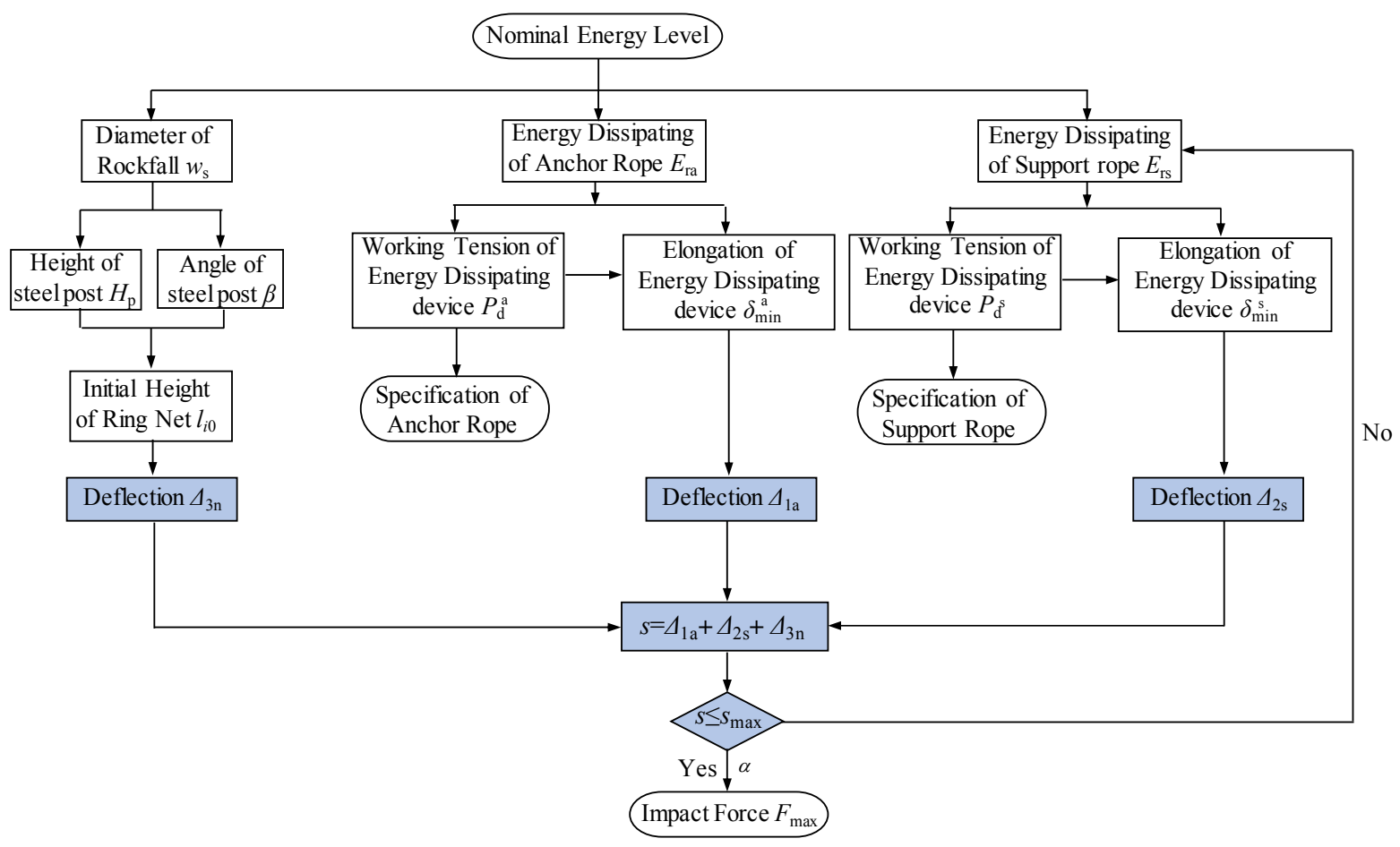

Figure 9. Design Procedure of Flexible Barrier System

In the full-scale test, the height of steel posts $H_{\mathrm{p}}$ is $5.5 \mathrm{~m}$, and the post is inclined upwards by $10^{\circ}$ in the vertical plane. The strength grade of steel posts is Q235. The specification of the steel wire ropes is $6 \times 19 \mathrm{~s}+\mathrm{IWR}$ (steel core) with tensile strength of $1770 \mathrm{MPa}$. The wire-ring net is manufactured by winding high strength steel wires with the diameter of $3 \mathrm{~mm}$ and the tensile strength of $1770 \mathrm{MPa}$ [23]. The energy dissipating devices used in the model are brake rings. The maximum elongation $(\delta)$ of a single brake ring is $1.1 \mathrm{~m}$, while the working forces $P_{\mathrm{a}}$ and $P_{\mathrm{s}}$ are 40 $\mathrm{kN}$ and $50 \mathrm{kN}$ respectively. The universal steel posts with wide-flange are fixed to the reaction wall by pin hinges, which enables the posts to rotate freely in the vertical plane and to rotate finitely in the horizontal plane. The arc-shaped steel plates are constructed on the post caps to reduce the friction effect and to increase the bending radius, also a specific construction is applied for the post foot to ensure smooth sliding of support ropes, as illustrated in Figure 10. The layout of energy dissipating devices and the load cells are shown in Figure 8.

Table 2 shows the details of all main components, the mechanical properties of the energy dissipating devices and deformation of each component based on the analytical solution presented in the companion paper. Energy dissipating ratio in Table 2 refers the ratio between the capacity of the energy dissipating device and the nominal energy level of the system. In particular, the energy dissipating ratio of the upslope anchor rope only involves the ropes connected to the inner post, rather than all the brake rings on the upslope anchor ropes. 
Table 2. The Parameters of Main Components

\begin{tabular}{|c|c|c|c|c|c|c|}
\hline \multirow{2}{*}{\multicolumn{2}{|c|}{ Component }} & \multirow[b]{2}{*}{ Specification } & \multicolumn{3}{|c|}{ Energy dissipating device } & \multirow[b]{2}{*}{ Deflection } \\
\hline & & & $\begin{array}{c}\text { Energy } \\
\text { dissipating ratio }\end{array}$ & $P_{\mathrm{a}} \sim P_{\mathrm{s}}$ & $\delta$ & \\
\hline Ring net & & $\mathrm{R} 16 / 3 / 300$ & & - & & $\Delta_{1 \mathrm{a}}=3.06 \mathrm{~m}$ \\
\hline \multirow{7}{*}{$\begin{array}{l}\text { Steel wire } \\
\text { rope }\end{array}$} & $\begin{array}{l}\text { Upper primary } \\
\text { support }\end{array}$ & $2 \varphi 22$ & $18.9 \%$ & $80 \sim 100 \mathrm{kN}$ & $2.1 \mathrm{~m}$ & \multirow{5}{*}{$\Delta_{2 \mathrm{~s}}=4.18 \mathrm{~m}$} \\
\hline & $\begin{array}{l}\text { Lower primary } \\
\text { support }\end{array}$ & $2 \varphi 22$ & $18.9 \%$ & $80 \sim 100 \mathrm{kN}$ & $2.1 \mathrm{~m}$ & \\
\hline & $\begin{array}{l}\text { Upper secondary } \\
\text { support }\end{array}$ & $1 \varphi 22$ & $9.5 \%$ & $40 \sim 50 \mathrm{kN}$ & $2.1 \mathrm{~m}$ & \\
\hline & $\begin{array}{c}\text { Lower secondary } \\
\text { support }\end{array}$ & $1 \varphi 22$ & $9.5 \%$ & $40 \sim 50 \mathrm{kN}$ & $2.1 \mathrm{~m}$ & \\
\hline & Lateral support & $1 \varphi 22$ & $4.5 \%$ & $40 \sim 50 \mathrm{kN}$ & $1.1 \mathrm{~m}$ & \\
\hline & Upslope anchor & $1 \varphi 22$ & $19.8 \%$ & $80 \sim 100 \mathrm{kN}$ & $1.1 \mathrm{~m}$ & \multirow[t]{2}{*}{$\Delta_{3 \mathrm{n}}=0.48 \mathrm{~m}$} \\
\hline & Lateral anchor & $1 \varphi 22$ & \multicolumn{3}{|c|}{-} & \\
\hline Steel post & & HW200×200 & \multicolumn{3}{|c|}{-} & \\
\hline
\end{tabular}

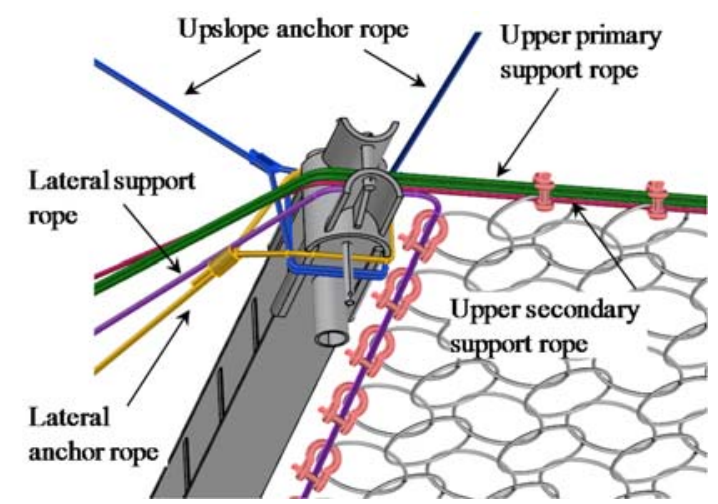

(a) Cap of edge post

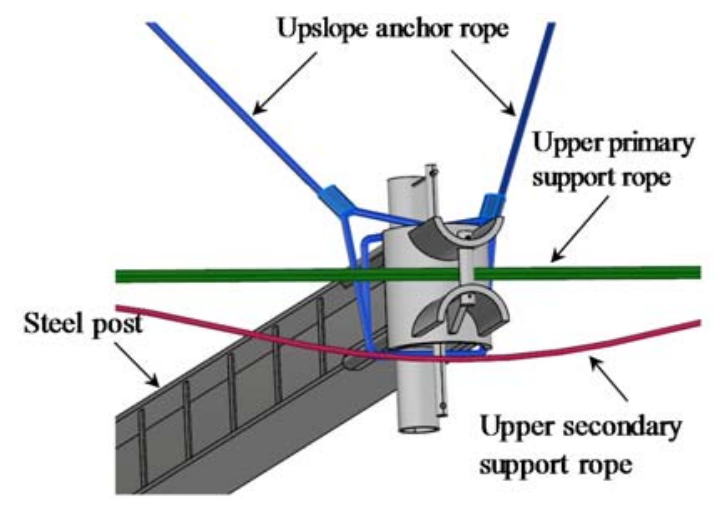

(c) Cap of inner post

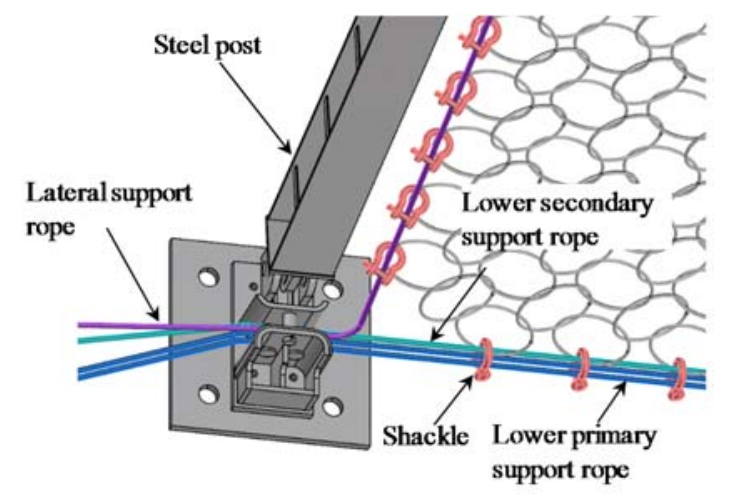

(b) Foot of edge post

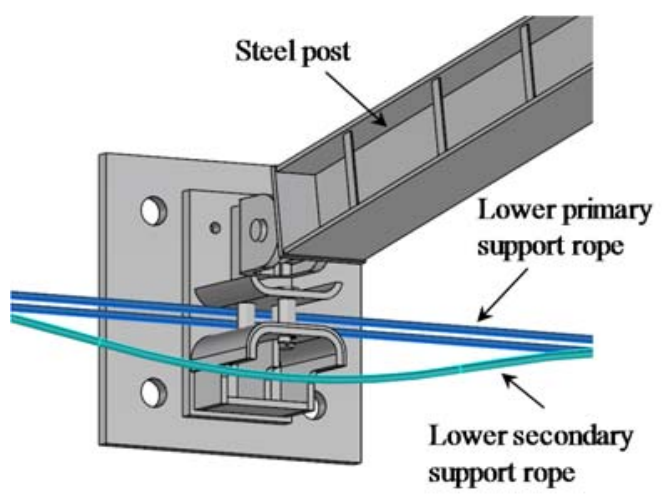

(d) Foot of inner post

Figure 10. Construction Details of Steel Post 
The model for the full-scale test has three functional modules. The photos in Figure 11 show the full-scale test model before impact test.

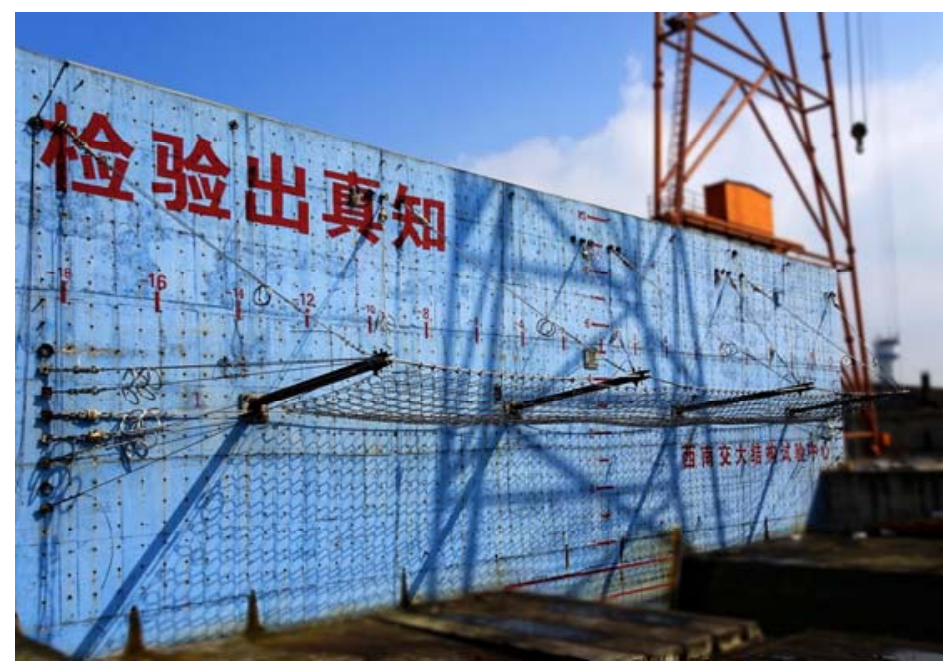

(a) Axonometric view

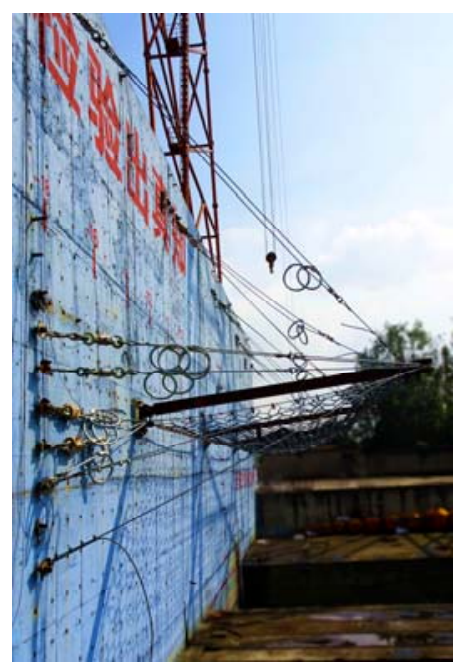

(b) Side view

Figure 11. Full-scale Test Model before Impact Test

\subsection{Test Setup}

The Full-scale impact test was conducted in the National Engineering Laboratory for Prevention and Control of Geological Disasters in Land Transportation of Southwest Jiaotong University (Sichuan, China). The experimental test system mainly consists of reaction wall, impact pool, traveling portal crane, impactor, high-speed camera, load cells, and data acquisition instrument, as shown in Figure 12. The impact test was conducted according to the European and U.S. standards $[21,24-26]$. The impactor is a polyhedral reinforced concrete block and weighs 6 tons. During the test, the traveling portal crane was used to lift the impactor to a target height of 34 meters, aiming at the central point of the middle functional module and then releasing the impactor freely, which can generate a velocity of $26 \mathrm{~m} / \mathrm{s}$ to impact the barrier structure. The high-speed camera was used to record the whole process of impacting, monitoring the deformation of system and the elongation of energy dissipating devices. The acceleration versus time curve of impactor can be obtained by differential of the velocity-time curve, and then the time-history curves of impact force of impactor can be also obtained. In addition, the tensile force versus time curves of the support ropes and the anchor ropes can be obtained by the load cells which were pre-arranged on the ropes. The sampling frequency of the test is $1 \mathrm{kHz}$. 


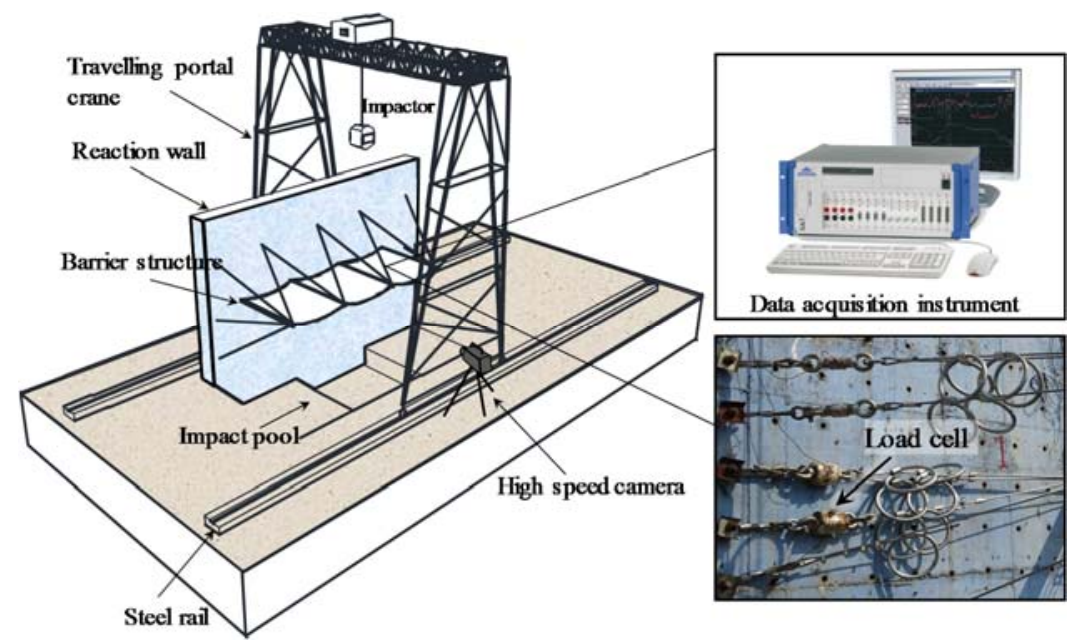

Figure 12. Artificial Test Site and Experimental Equipment

\subsection{Performance of the Proposed System}

The numerical modeling approach used in the previous companion paper is adopted to build a numerical model with energy level of $2000 \mathrm{~kJ}$ [3, 4, 21]. Form-finding analysis [27-29] of the model has been done before the impact process. The mechanical behavior of the deflection-control-based system under the impact load is investigated by the full-scale test and numerical simulation. At the same time, the accuracy of the numerical simulation used in this paper can be verified by the full-scale test results, so that the following parametric analysis can be further conducted based on the numerical model.

The curves of displacement versus time and impact force versus time from full-scale test are plotted in Figure 13 against the numerical simulation results. It can be seen that the deflection-controlbased flexible barrier system has no clear peak internal force under the impact of rockfall. Figure 14 compares the results of the full-scale test (first column) and the numerical simulation (second column) at the four typical moments during the whole impact: (1) impactor began to contact with the ring net; (2) the energy dissipating devices on support ropes was activated; (3) the maximum displacement of impactor was reached and; (4) the impactor rebounded and finally stopped. The third column depicts the z-location of the impactor measured by the full-scale test. Both the full-scale test and numerical simulation show that the deflection-control-based flexible barrier system has a three-stage deflection characteristic under the impact of rockfall $[3,4]$.

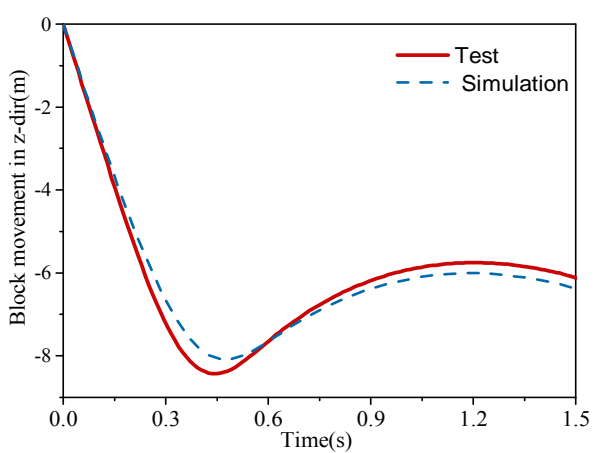

(a) Displacement time-history of the block

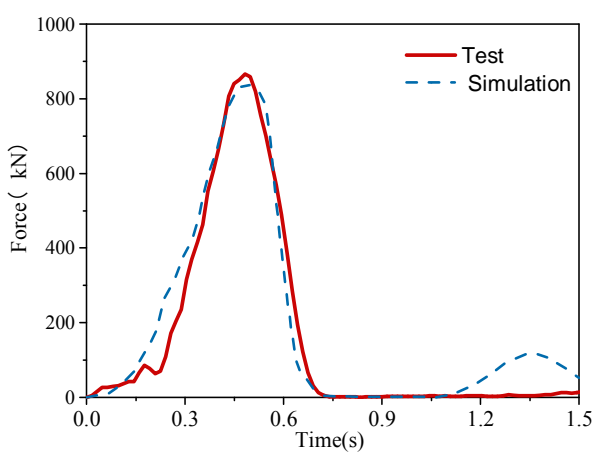

(b) Impact force time-history of the block

Figure 13. Deflection and Force Responses 

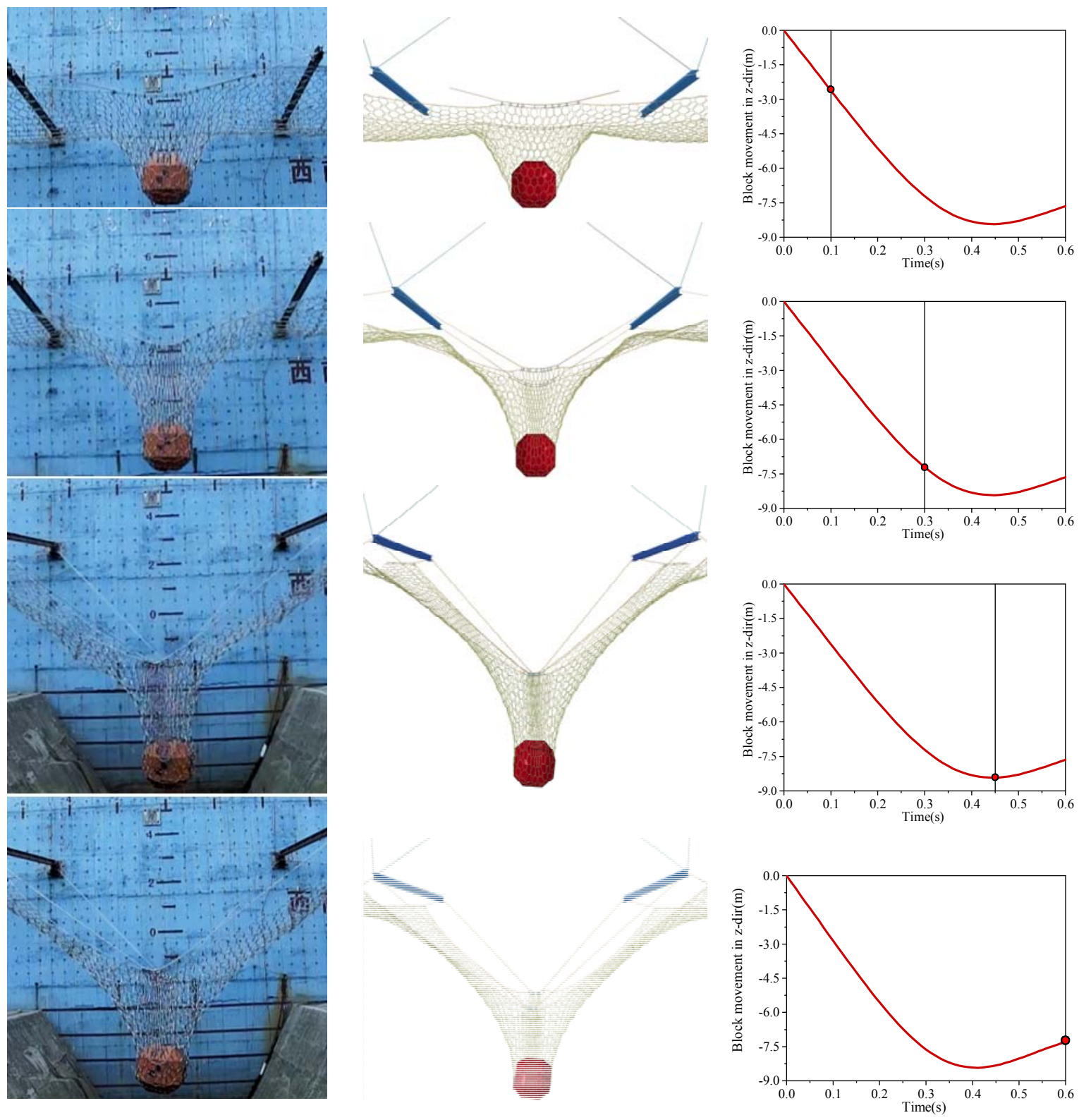

Figure 14. Deformed Shapes at Typical Moments (Test vs. Simulation)

After the impact test, all energy dissipating devices were activated. The energy dissipating devices mounted on support ropes show good utilization. Especially the energy dissipating devices mounted on the lower support ropes almost reaches the ultimate elongation, as shown in Figure 15(a,b). The energy dissipating devices mounted on upslope anchor ropes (L5, L6) in the impact zone also reaches the ultimate elongation, as shown in Figure $15(\mathrm{c}, \mathrm{d})$. The maximum elongation of the energy dissipating devices mounted on the adjacent upslope anchor ropes (L4, L7) was small and around $0.2 \mathrm{~m}$. Because the edge functional modules are not directly subjected to impact load, the elongation of energy dissipating devices mounted on the upslope anchor ropes was also small. In general, the system still has safety reserves. The performance of system is checked according to European standards [21], and the key parameters are shown in Table 3. 


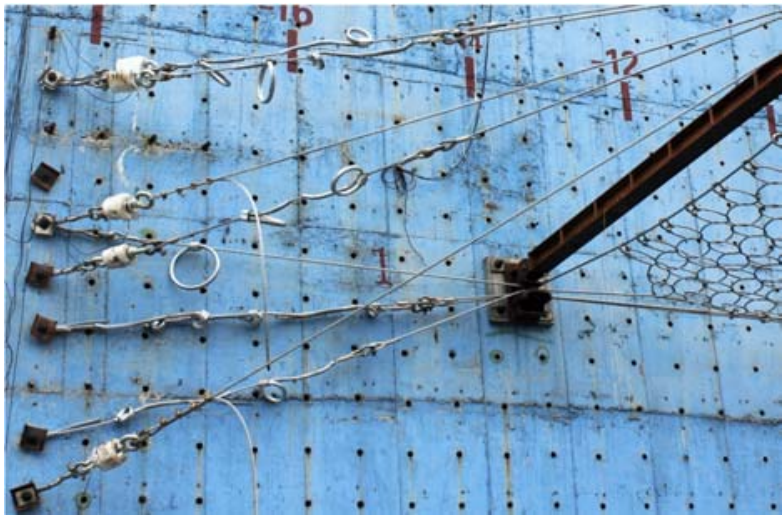

(a) Left support rope

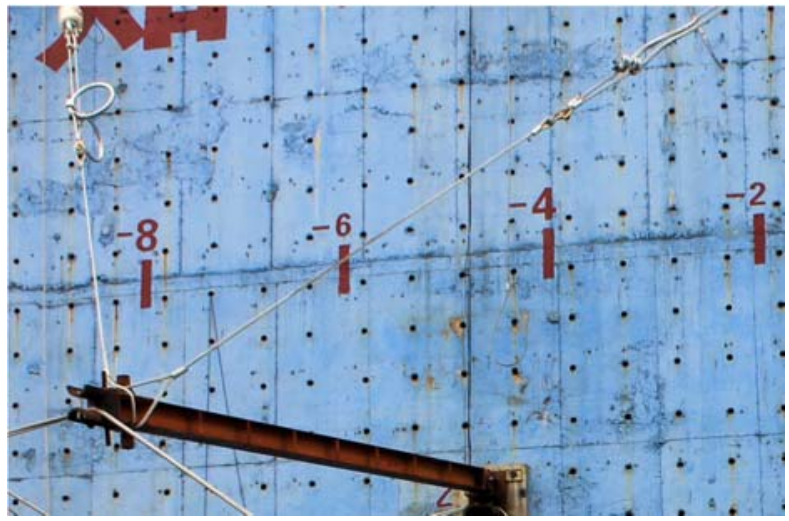

(c) Upslope anchor ropes 4,5

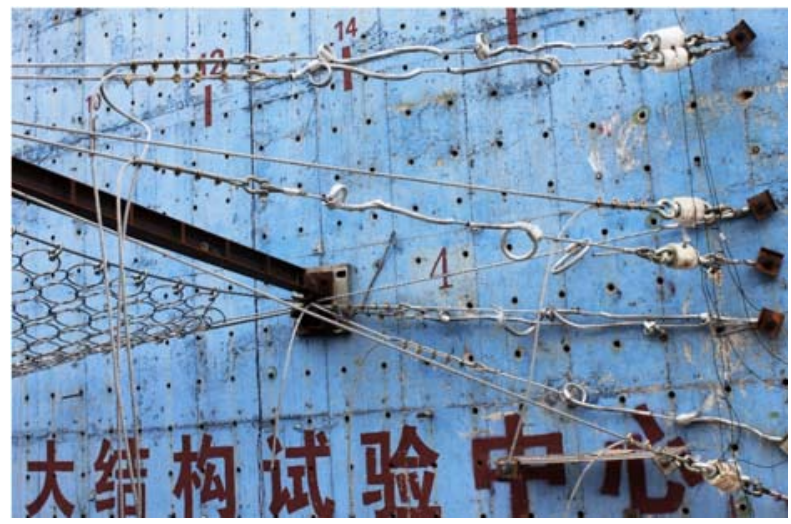

(b) Right support rope

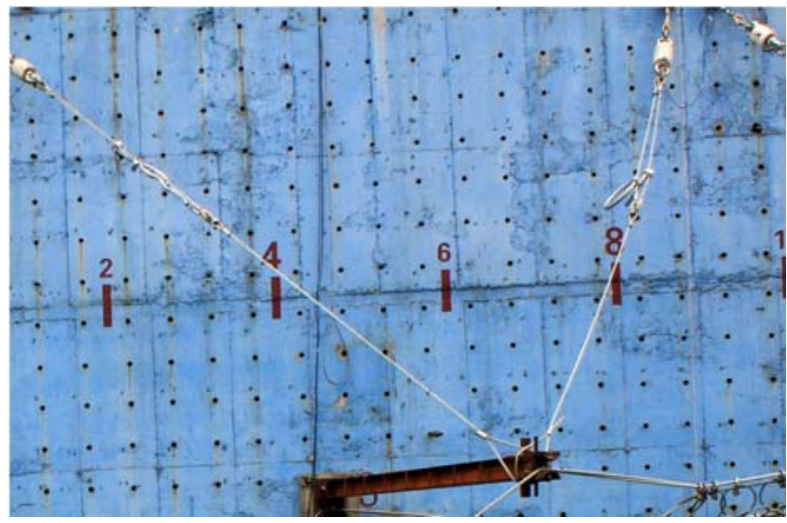

(d) Upslope anchor ropes 6,7

Figure 15. Elongations of Energy Dissipating Devices

Table 3. Comparison of Key Parameters between Test and Simulation

\begin{tabular}{ccccc}
\hline Impact & $\begin{array}{c}\text { Nominal height } \\
h_{\mathrm{N}}(\mathrm{m})\end{array}$ & $\begin{array}{c}\text { Residual height } \\
h_{\mathrm{R}}(\mathrm{m})\end{array}$ & $h_{\mathrm{R}} / h_{\mathrm{N}}$ & $\begin{array}{c}\text { Maximum impact } \\
\text { deflection }(\mathrm{m})\end{array}$ \\
\hline Test & 5.245 & 2.905 & $55.39 \%$ & 8.426 \\
Simulation & 5.186 & 2.718 & $52.41 \%$ & 8.084 \\
Difference & $1.12 \%$ & $6.44 \%$ & $5.38 \%$ & $4.06 \%$ \\
\hline
\end{tabular}

Note: $h_{\mathrm{N}}$ is the nominal height and $h_{\mathrm{R}}$ is the residual height.

It can be seen from Table 3 that the difference between full-scale test and numerical simulation is small. Both the results of test and simulation show that $h_{\mathrm{R}} / h_{\mathrm{N}}>50 \%$, reaching the class A for the standard [17]. The results show that the deflection-control-based flexible rockfall barrier system has the good performance under the impact load. In addition, the impact deflection of the system is $7.720 \mathrm{~m}$ and $8.426 \mathrm{~m}$ obtained from analytical solution and full-scale test respectively. The difference between them is $9.1 \%$ and therefore the proposed method in the companion paper is good for engineering practice. The error may be from the approximate behavior of energy dissipating devices assumed in the analytical solution. 
After the test, the inner posts swing laterally, while the edge posts were slightly upturned. No buckling and damage were found in all steel posts, seen in Figure 15. Figure 16 shows the time-history curves of internal force of rope obtained in full-scale test and numerical simulation, as well as the nominal breaking force of the steel wire rope [23]. Figure 16(a-c) shows the curves of force versus time of support ropes. It can be seen that, from 0 second to 0.1 second, the system was rapidly changed from loose state to tighten state. The internal force of the support ropes increased very fast and approaching to the activation force of the energy dissipating devices. After 0.1 second, the energy dissipating devices mounted on the support ropes are activated and the plastic tensile deformation was developed. The support ropes began to slide along the ends of the post and the internal force increased steadily. The funnel-shaped deflection was finally developed.

Figure 16(d-g) shows the curves of force versus time of anchor ropes. It can be seen that, after 0.3 second, the energy dissipating devices mounted on the upslope anchor ropes were activated and the plastic tensile deformation was generated, making the steel post swing downward. At the same time, the internal forces of support ropes increased steadily, and the system continued to dissipate energy. At 0.4 second, the energy dissipating devices mounted on the upslope anchor rope L5, L6 stopped working after reaching the ultimate elongation and as a result, the corresponding internal force on the upslope anchor ropes increased sharply to a peak force, seen in Figure 16(e, f). However, the internal forces of upslope anchor ropes L4 and L7 in the non-impact zone were small, as seen in Figure $16(\mathrm{~d}, \mathrm{~g})$. After 0.4 second, the internal force of support ropes kept increasing steadily, and the maximum value of the internal force appeared at about 0.45 second. After that, all the ropes were unloaded and the rockfall rebounded. During the first impact process, the working time of the energy dissipating devices were about 0.35 second. Under the impact load, the dynamic response of the ropes was small and the peak internal force was low. Thus, no breaking of the components was found and the system shows good performance with safety reserve.

For the support ropes, as mentioned above, since the load cells were mounted near the anchorages of support ropes, the results obtained by the load cells were the internal forces of ropes at the anchorages. However, due to the friction effect, the internal force of the support rope is attenuated from the impact zone to both sides. It means that the internal force at the anchorages was less than the internal force in the impact zone. Thus, the support ropes in the impact zone have larger safety reserve larger than other ropes.

The curves of force versus time of ropes obtained by the numerical simulation agree well with results of the full-scale test. The numerical simulation reproduces the entire impact process well. It should be noted that the lateral anchor ropes are used to prevent large lateral swing of the steel post and maintain the stability of the posts and therefore, the energy dissipating devices are not required. In Figure 16h, the difference between the curves of the internal force of lateral anchor rope may essentially be caused by the slack of the rope due to the blemish of the model installation.

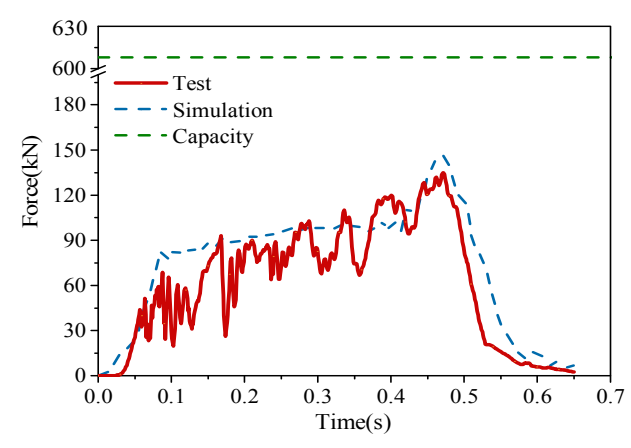

(a) Upper primary support rope L1

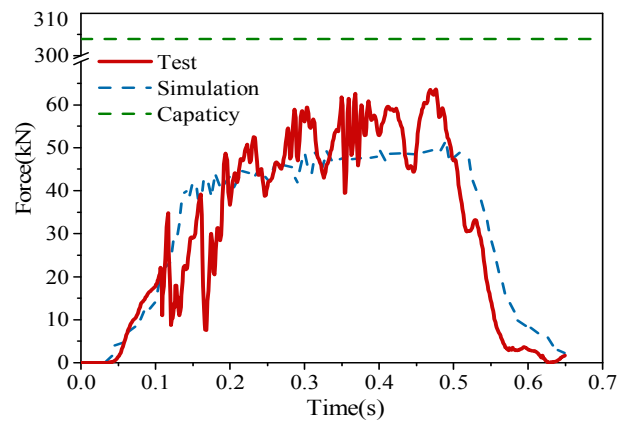

(b) Upper secondary support rope L2 


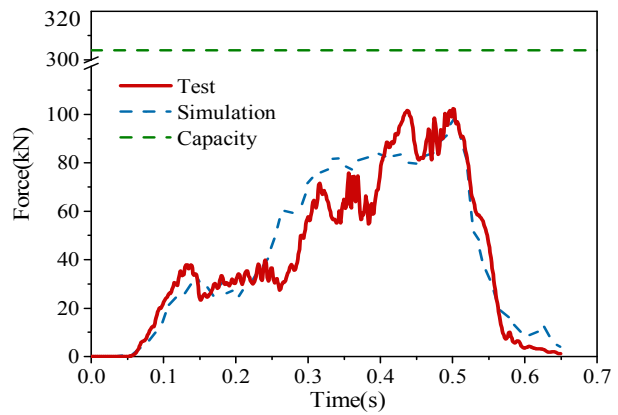

(c) Lateral support rope L3

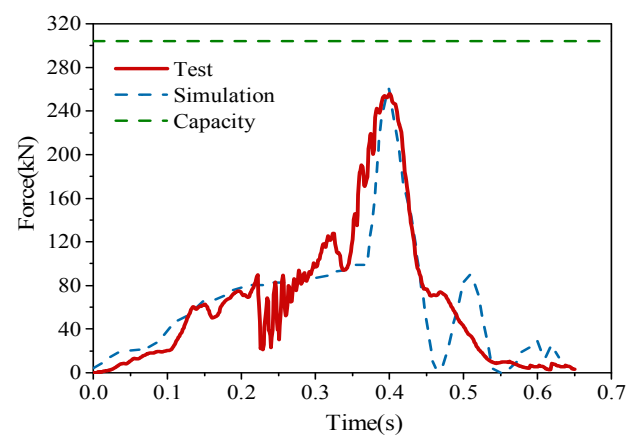

(e) Upslope anchor rope L5

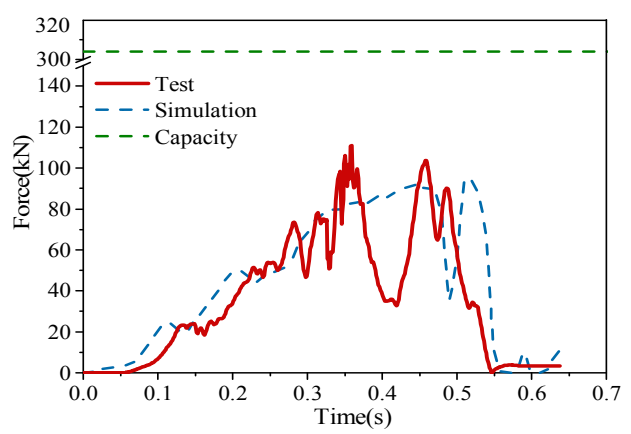

(g) Upslope anchor rope L7

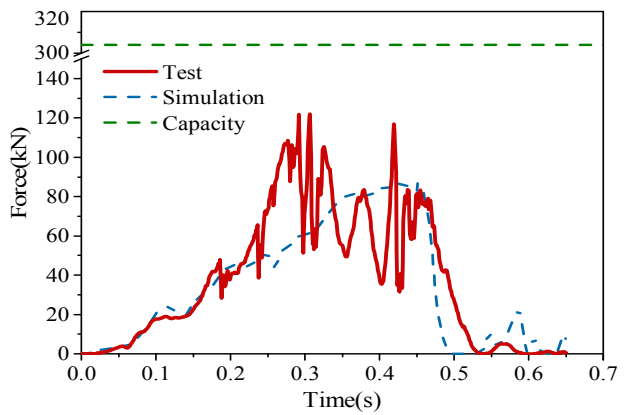

(d) Upslope anchor rope L4

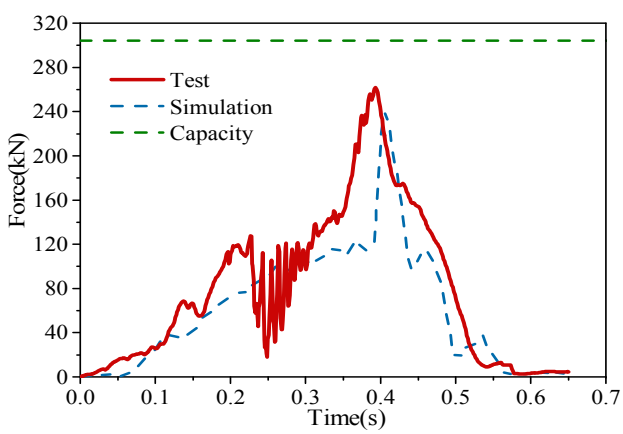

(f) Upslope anchor rope L6

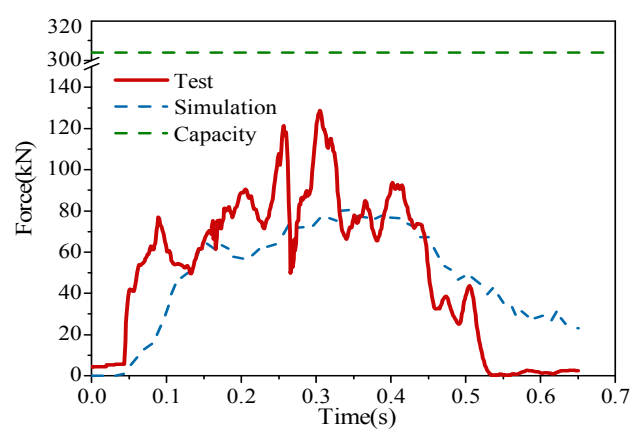

(h) Lateral anchor rope L8

Figure 16. Comparison of Force Responses between Test and Simulation

\section{PARAMETRIC STUDY FOR BUFFER PERFORMANCE CONTROL}

As mentioned above, the plastic deformation of the energy dissipating devices is vital to realize the buffer mechanics and achieve the structural performance of the system. In order to further investigate the influence of plastic deformation of energy dissipating devices on the system response, eight different numerical models for parametric study are built with different force-displacement relationships of the energy dissipating devices on support ropes. As the difference between $P_{\mathrm{a}}$ and $P_{\mathrm{s}}$ is small, the working force of the energy dissipating device will be simplified as $P_{\mathrm{a}}=P_{\mathrm{s}}$. Taking the energy dissipating devices on primary support ropes as an example, the $P-\delta$ curve is shown in Figure 17. Due to the same capacity of energy dissipation of the eight groups of energy dissipating devices, the envelope areas all curves are equal. The parameters of the energy dissipating devices in Table 4 are summarized for practical engineering. The parameters associated with the energy dissipating devices on the lateral support ropes and the upslope anchor 
ropes are same as shown in Table 2. According to the results of the numerical simulation, the eight groups of models successfully intercepted the rockfall, and the processes of impact deflection are similar to that in Figure 14. The difference is only the system deflection, the response of internal force and the efficiency of the energy dissipating devices, which will be discussed in detail later.

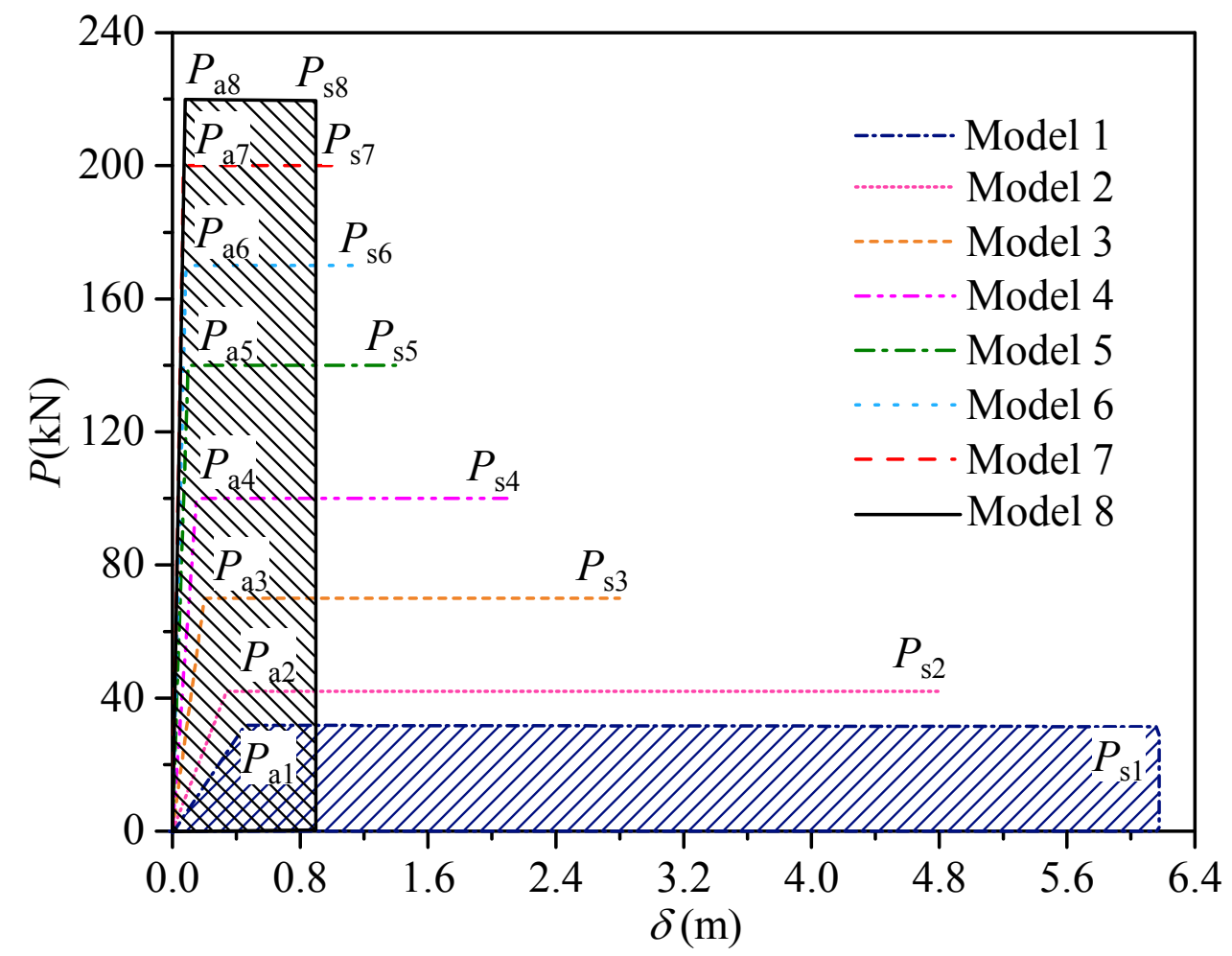

Figure 17. Performance Parameters of Energy Dissipating Devices

Table 4. The Parameters of Energy Dissipating Devices

\begin{tabular}{ccccccccc}
\hline \multirow{2}{*}{ Model } & \multicolumn{2}{c}{$\begin{array}{c}\text { Upper primary } \\
\text { support rope }\end{array}$} & \multicolumn{2}{c}{$\begin{array}{c}\text { Lower primary } \\
\text { support rope }\end{array}$} & \multicolumn{2}{c}{$\begin{array}{c}\text { Upper secondary } \\
\text { support rope }\end{array}$} & \multicolumn{2}{c}{$\begin{array}{c}\text { Lower secondary } \\
\text { support rope }\end{array}$} \\
\cline { 2 - 8 } & $P_{\mathrm{a} \sim P_{\mathrm{s}}(\mathrm{kN})} \delta(\mathrm{m})$ & $P_{\mathrm{a} \sim P_{\mathrm{s}}(\mathrm{kN})} \delta(\mathrm{m})$ & $P_{\mathrm{a} \sim P_{\mathrm{s}}(\mathrm{kN})} \delta(\mathrm{m})$ & $P_{\mathrm{a} \sim P_{\mathrm{s}}(\mathrm{kN})} \delta(\mathrm{m})$ \\
\hline 1 & $32 \sim 32$ & 6.20 & $32 \sim 32$ & 6.20 & $16 \sim 16$ & 6.20 & $16 \sim 16$ & 6.20 \\
2 & $42 \sim 42$ & 4.80 & $42 \sim 42$ & 4.80 & $21 \sim 21$ & 4.80 & $21 \sim 21$ & 4.80 \\
3 & $70 \sim 70$ & 2.80 & $70 \sim 70$ & 2.80 & $35 \sim 35$ & 2.80 & $35 \sim 35$ & 2.80 \\
4 & $100 \sim 100$ & 2.10 & $100 \sim 100$ & 2.10 & $50 \sim 50$ & 2.10 & $50 \sim 50$ & 2.10 \\
5 & $140 \sim 140$ & 1.40 & $140 \sim 140$ & 1.40 & $70 \sim 70$ & 1.40 & $70 \sim 70$ & 1.40 \\
6 & $170 \sim 170$ & 1.20 & $170 \sim 170$ & 1.20 & $85 \sim 85$ & 1.20 & $85 \sim 85$ & 1.20 \\
7 & $200 \sim 200$ & 1.00 & $200 \sim 200$ & 1.00 & $100 \sim 100$ & 1.00 & $100 \sim 100$ & 1.00 \\
8 & $220 \sim 220$ & 0.90 & $220 \sim 220$ & 0.9 & $110 \sim 110$ & 0.90 & $105 \sim 105$ & 0.90 \\
\hline
\end{tabular}




\subsection{Discussion on Deflection}

In order to investigate the influence of the performance parameters of the energy dissipating devices on the system response, the deflection of support structure $\left(\Delta_{1 \mathrm{a}}\right)$, sliding movement of support rope $\left(\Delta_{2 s}\right)$, puncturing deflection of ring net $\left(\Delta_{3 n}\right)$ and the overall system deflection $(s)$ are extracted from numerical simulation, compared with the analytical solutions as shown in Table 5. In general, with the increase of working force of the energy dissipating devices, $s$ decreased significantly. For example, $s$ in model 8 is about $50 \%$ of that in model 1 , and the deflection decreased is more than 5 meters. Therefore, in practical application, the performance parameters of the energy dissipating devices can be adjusted to control the buffer deformation of the system to meet the design limit. It can be seen from Table 5 that the analytical solution of $s$ is in good agreement with the numerical solution. However, the difference between the analytical solution $\Delta_{1 \mathrm{a}}$ and the numerical solution $\Delta_{1 \mathrm{a}}$ of the model 1 is up to $20.5 \%$. It is because the working force of the energy dissipating devices on support ropes in model 1 is small and the elongation of energy dissipating devices and the sliding of support ropes are large, which leads to the buffer deformation of the system is very large and the corresponding impact force is small. The overload protection provided by the energy dissipating devices causes the vertical component of the impact load is not enough to make the energy dissipating devices on the upslope anchor rope fully work. In other words, when using the analytical method to calculate $\Delta_{1 \mathrm{a}}$, the empirical coefficient of the stretching efficiency used in the energy dissipating devices is greater than that in the numerical model. Thus, the analytical solution $\Delta_{1}$ is larger than that in numerical simulation. It should be noted that, in the models 1 and 2, as the elongation of the energy dissipating devices on secondary support ropes is restricted by the ultimate stretching length $\left(\Delta_{\text {trans }}\right)$ of the ring net along the bypassed length, the development of $\Delta_{2 s}$ is limited. However, the primary support ropes and secondary support ropes are forced together and mutually restrain in the deflection-control-based system. For this reason, it is recommended to take the average elongation of energy dissipating devices mounted on primary support ropes and secondary support ropes when using the analytical method to calculate $\Delta 2$ s. The detailed calculation can be referred to Eq. 9 of the companion paper.

Table 5. Comparison of Deflections

\begin{tabular}{ccccccccc}
\hline Results & \multicolumn{1}{c}{$L_{\mathrm{la}}(\mathrm{m})$} & $L_{2 \mathrm{~s}}(\mathrm{~m})$ & $\angle \mathrm{n}(\mathrm{m})$ & \multicolumn{2}{c}{$s(\mathrm{~m})$} & \multicolumn{3}{c}{ Relative error (\%) } \\
\hline Model 1/ Analytical & $0.39 / 0.47$ & $7.55 / 7.39$ & $3.17 / 3.06$ & $11.11 / 10.92$ & 20.5 & 2.1 & 3.5 & 1.7 \\
Model 2/ Analytical & $0.44 / 0.47$ & $6.82 / 6.54$ & $3.18 / 3.06$ & $10.44 / 10.07$ & 6.8 & 4.1 & 3.5 & 3.5 \\
Model 3/ Analytical & $0.52 / 0.47$ & $5.22 / 5.03$ & $3.01 / 3.06$ & $8.79 / 8.56$ & 9.6 & 3.6 & 1.7 & 2.6 \\
Model 4/ Analytical & $0.49 / 0.47$ & $4.45 / 4.10$ & $3.15 / 3.06$ & $8.09 / 7.63$ & 4.1 & 7.9 & 2.9 & 5.7 \\
Model 5/ Analytical & $0.45 / 0.47$ & $3.55 / 3.05$ & $3.02 / 3.06$ & $7.02 / 6.58$ & 4.4 & 14.1 & 1.3 & 6.3 \\
Model 6/ Analytical & $0.46 / 0.47$ & $3.16 / 2.72$ & $3.01 / 3.06$ & $6.63 / 6.25$ & 2.2 & 13.9 & 1.7 & 5.7 \\
Model 7/ Analytical & $0.48 / 0.47$ & $2.58 / 2.35$ & $2.91 / 3.06$ & $5.97 / 5.88$ & 2.1 & 8.9 & 5.2 & 1.5 \\
Model 8/ Analytical & $0.52 / 0.47$ & $2.38 / 2.16$ & $2.88 / 3.06$ & $5.78 / 5.69$ & 9.6 & 9.26 & 6.3 & 1.6 \\
\hline
\end{tabular}

\subsection{Discussion on Rope Force}


To investigate the influence of the performance parameters of the energy dissipating devices on the internal force of ropes, the time-history curves of internal force of the ropes are extracted from the numerical simulation, as shown in Figure 18. As the models are symmetrically arranged, only the results of the upper primary support rope L1, the upper secondary support rope L2, the upslope anchor rope L4 and the upslope anchor rope L5 are extracted from the numerical simulation, and the number of ropes is shown in Figure 8. As the ropes are affected by the overload protection provided by the energy dissipating devices, the development of internal force on the ropes and the working force of the energy dissipating devices is similar. The internal force of ropes has clear yield stage which is positive correlation with the working force of the energy dissipating devices, as shown in Figure 18(a,b). Meantime, with the increase of elongation of energy dissipating devices, the duration of the yield stage also increases significantly, leading to effectively reduce the impact force on the system.

For the support ropes, the peak internal force of the primary support ropes in the model 3 and model 4 appears after 0.4 second. The reason is that the designed elongation of energy dissipating devices is slightly short which can be improved by increasing the potential elongation of the energy dissipating devices. In model 3, there are similar characteristics in internal force of secondary support ropes with the same reason. In the other models, the internal forces of support ropes are stable, indicating that the corresponding parameters of energy dissipating devices in these models are more favorable for the overload protection of the system.

For the upslope anchor ropes, the rope L4 in the non-impact zone and the rope L5 in the impact zone show a significantly different dynamic response. The internal force of the upslope anchor rope L4 is generally small because it is not directly subjected to impact load, and the maximum value of force is the same, as shown in Figure 18c. The change regulation of force response of anchor rope L5 in the impact zone can be analyzed in combination with Table 5. With the reduction of the working force of the energy dissipating devices on support ropes, the buffer deformation of system increase while the impact force will be reduced. Thus, the internal force of the anchor rope and the elongation of the energy dissipating devices on anchor ropes will also be reduced. When the actual elongation of the energy dissipating devices is less than the designed elongation, the rope will be in the state of overload protection.

In models 1 to 4, the yielding stage of upslope anchor rope L5 remains stable, seen in Figure 18d. In contrast, the internal force of the anchor rope L5 in model 5-8 shows significant peak value. It is because the increase of impact force on the system causes more significant elongation of energy dissipating devices, and therefore the designed elongation should be increased. In practical design, the increase of the working force of energy dissipating devices will improve the overload protection capacity for both the components and the system, by appropriately increasing the design elongation.
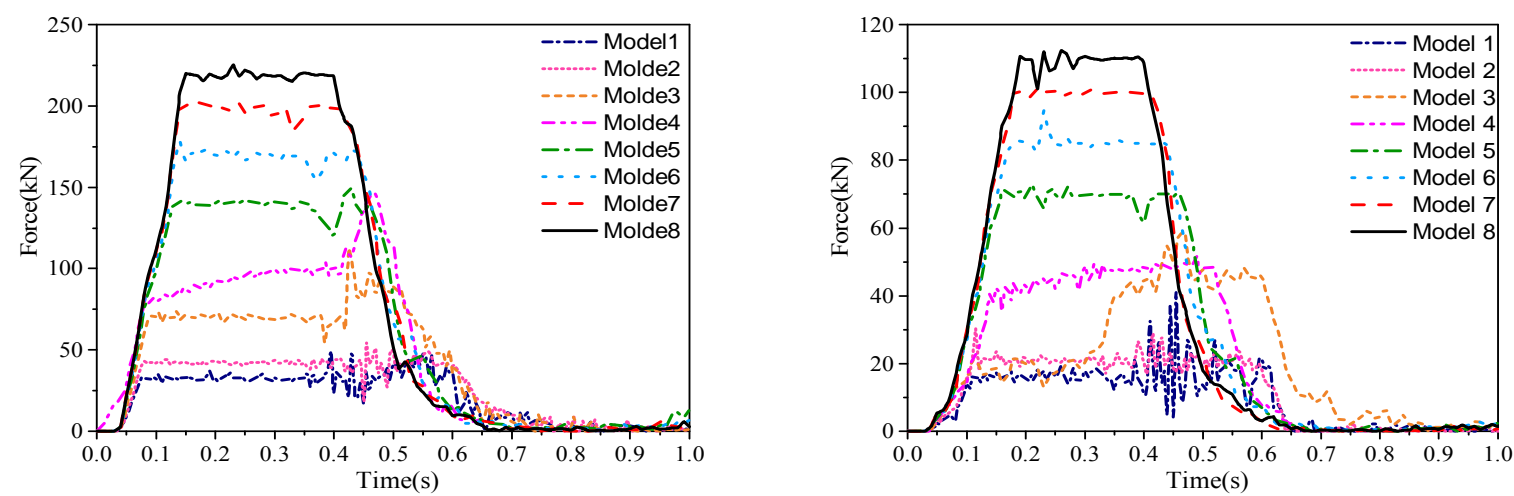
(a) Upper primary support rope L1

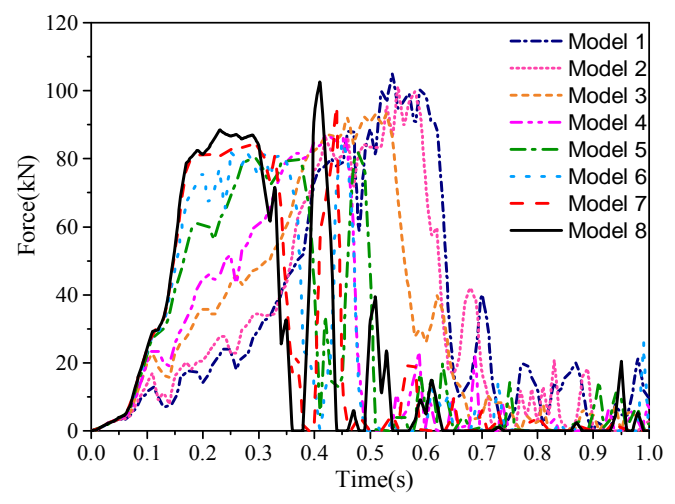

(c) Upslope anchor rope L4 (b) Upper secondary support rope L2

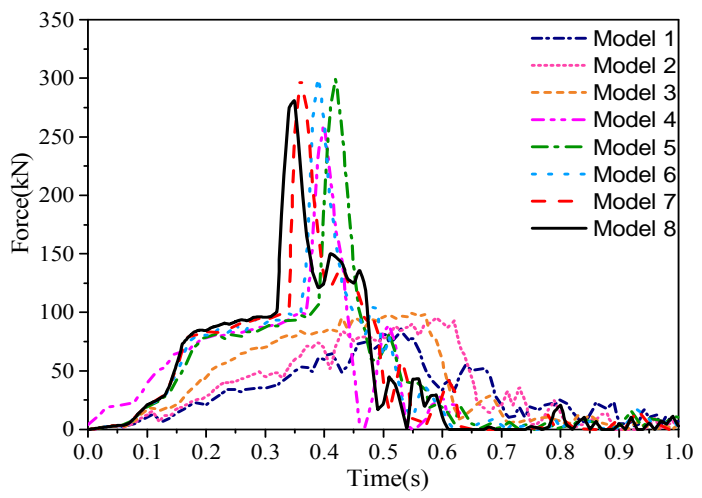

(d) Upslope anchor rope L5

Figure 18. Time-History Curves of Ropes

\subsection{Energy Dissipation and Control}

To investigate the influence of the performance parameters of the energy dissipating devices on the energy dissipation of system, the analysis results of energy dissipation of the energy dissipating devices on the support ropes and the upslope anchor ropes are extracted from the numerical simulation, as shown in Table 6. In the table, the contribution ratio is obtained from the actual energy dissipation of the energy dissipating devices over the nominal energy of the system. The utilization ratio is calculated from the actual energy dissipation of the energy dissipating devices over the designed energy dissipation. Taking model 3 as an example, with the decreasing of the working force of the energy dissipating devices, the contribution ratio and the utilization ratio of the energy dissipating devices are reduced. Meanwhile, with the increasing of the working force of the energy dissipating devices, the contribution ratio and the utilization ratio are also reduced. The parameters of energy dissipating devices in model 3 show relatively superior characteristics. As mentioned above, the energy dissipation ratio of the energy dissipating devices keeps as $80 \%$ in the design stage. Hence, if the working force decreases, the allowable elongation of the energy dissipating devices should be increased. Taking model 1 and model 4 as examples, the designed elongation of energy dissipating device in model 1 is 6.2 meters, an increase of about $200 \%$ compared to model 4, which directly leads to the increase of $\Delta 2 \mathrm{~s}$. However, as mentioned in the companion paper, the actual elongation of energy dissipating devices on the support ropes is also restricted by $\Delta$ trans, which inhibits the internal force from transmitting to the anchorages of support ropes. Thus, it is impossible for the energy dissipating devices on the support ropes to be fully stretched, resulting in the decrease in contribution ratio and utilization ratio. At the same time, the development of $\Delta_{2 \mathrm{~s}}$ is also restricted. Taking models 4 to 8 as the examples, as the nominal energy levels of the systems are identical, the increase of the designed elongation of the energy dissipating devices is difficult due to increase of the working force simultaneously. As a result, the energy dissipating devices cannot be fully stretched and the contribution ratio and utilization of energy dissipating device are also decreased. The results of the parametric analysis show that the optimal elongation and corresponding working force can be determined in energy dissipating devices to obtain the best buffering performance of the system. Combined with the designed parameters in Table 4 and analysis results in Table 6 for the models 3 and 4, the optimal elongation of the energy dissipating devices can be determined by trial-and-error calculation. The upper limit of elongation is $\Delta$ trans as mentioned in the companion paper. 
Table 6. Results of Numerical Simulation of Energy Dissipating Device

\begin{tabular}{cccccc}
\hline \multirow{2}{*}{ Model } & Nominal & \multicolumn{4}{c}{ Energy dissipating device } \\
\cline { 3 - 5 } energy levels & $\begin{array}{c}\text { Design energy } \\
\text { dissipating }\end{array}$ & $\begin{array}{c}\text { Actual energy } \\
\text { dissipating }\end{array}$ & Contribution ratio & Utilization ratio \\
\hline 1 & $2000 \mathrm{~kJ}$ & $1685 \mathrm{~kJ}$ & $1285 \mathrm{~kJ}$ & $64.3 \%$ & $76.3 \%$ \\
2 & $2000 \mathrm{~kJ}$ & $1705 \mathrm{~kJ}$ & $1400 \mathrm{~kJ}$ & $70.0 \%$ & $82.1 \%$ \\
3 & $2000 \mathrm{~kJ}$ & $1671 \mathrm{~kJ}$ & $1520 \mathrm{~kJ}$ & $76.0 \%$ & $91.0 \%$ \\
4 & $2000 \mathrm{~kJ}$ & $1755 \mathrm{~kJ}$ & $1442 \mathrm{~kJ}$ & $72.1 \%$ & $82.2 \%$ \\
5 & $2000 \mathrm{~kJ}$ & $1671 \mathrm{~kJ}$ & $1377 \mathrm{~kJ}$ & $68.9 \%$ & $82.4 \%$ \\
6 & $2000 \mathrm{~kJ}$ & $1719 \mathrm{~kJ}$ & $1354 \mathrm{~kJ}$ & $67.7 \%$ & $78.8 \%$ \\
7 & $2000 \mathrm{~kJ}$ & $1695 \mathrm{~kJ}$ & $1309 \mathrm{~kJ}$ & $65.5 \%$ & $77.3 \%$ \\
8 & $2000 \mathrm{~kJ}$ & $1683 \mathrm{~kJ}$ & $1288 \mathrm{~kJ}$ & $64.4 \%$ & $76.5 \%$ \\
\hline
\end{tabular}

In addition, the correlation between the impact force $(F)$ and buffer deflection $(s)$ is further studied. As the energy dissipating capacity of the barrier system is identical, with the increase of the working force of energy dissipating devices on the support ropes, $s$ gradually decreases while $\mathrm{F}$ increases. Thus, the slope of $F-s$ curves also increases gradually, which indicates that the stiffness of system increases gradually, as shown in Figure 19a. However, when the working force of energy dissipating device on support ropes increases to a certain limit, e.g. models 7 and $8, F$ tends to be stable and the change of $s$ is small. According to the companion paper, $\Delta 2 \mathrm{~s}$ accounts for more than half of the $s$ and plays a controlling role in the buffer deformation of the system when the buffer mechanism is functioned properly. However, with the increase of working force of the energy dissipating devices, the elongation of the energy dissipating devices decreases significantly, which makes $\Delta_{2 \mathrm{~s}}$ decrease significantly. Therefore, $s$ will depend on $\Delta_{1 \mathrm{a}}$ and $\Delta_{3 \mathrm{n}}$. However, $\Delta_{1 \mathrm{a}}$ is smaller than other deflection components, while $\Delta_{3 \mathrm{n}}$ is almost constant. As a result, the total deflection $s$ tends to be stable when the working tension of the energy dissipating devices on support ropes increases to a certain value. This rule can be used to determine the upper limit threshold of the working force of energy dissipating devices in the actual design.

Figure $19 \mathrm{~b}$ shows the correlation between the working force of the energy dissipating devices on the support ropes and the elongation of the system, and the numbers in parentheses indicate the design elongation of the energy dissipating devices. According to the previous analysis, it is not beneficial to enhance the buffer performance of the system when working force of energy dissipating devices is too large or too small. Hence, the parameters of energy dissipating devices on the support ropes in models 3 to 6 can be used as the control interval. Taking the point A in Figure $19 \mathrm{~b}$ as an example, when the working force of energy dissipating devices on the support ropes is the same as that in model 5, the designed elongation may range from $1.4 \mathrm{~m}$ to $2.8 \mathrm{~m}$. In other words, when $s$ does not allow to exceed $8.0 \mathrm{~m}$ due to the protection requirement within a limit, the working force of energy dissipating devices on the support ropes can be 150 to $255 \mathrm{kN}$. Apparently, this provides a practical approach for selection or design of flexible barrier product. 


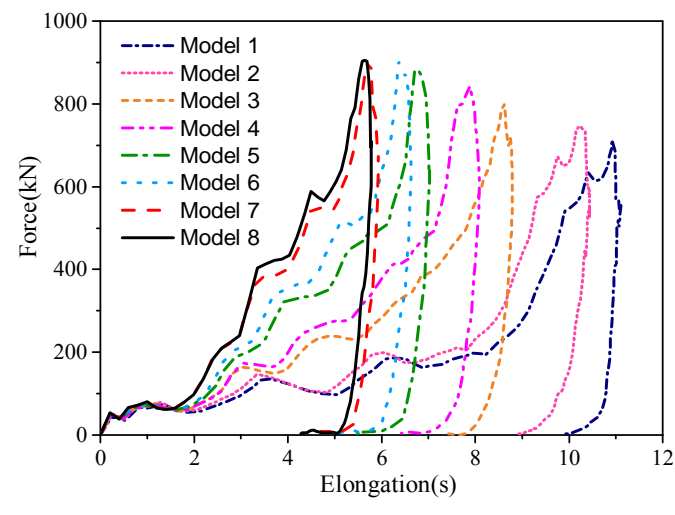

(a) $F$-s curves of System

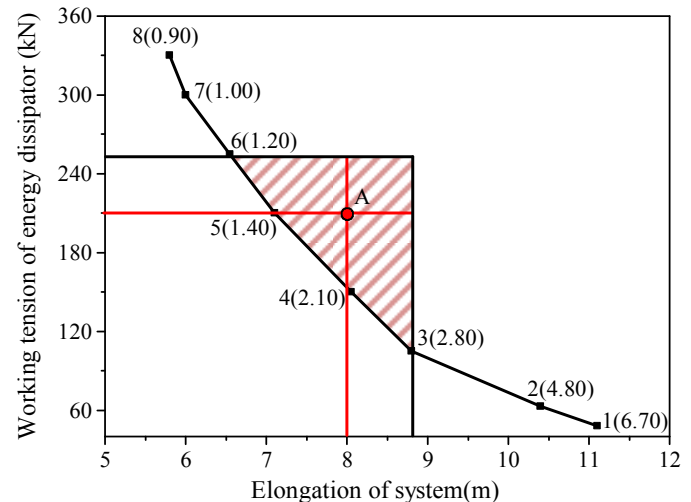

(b) Performance Control and Parameters Interval

Figure 19. Results of Parametric Analysis

\section{CONCLUSIONS}

This paper establishes a deflection-control-based mechanical model with improved buffer performance. A prototype model with a nominal energy level of $2000 \mathrm{~kJ}$ was designed using the analytical method introduced in part one of the paper. Both full-scale test and numerical simulation were carried out to investigate the response of the prototype model under impact load. The results show that the motion interference and the braking effect during impact test are effectively controlled by the proposed deflection-control-based mechanical model, leading to an optimized design regarding system buffer performance. In summary, the following conclusions can be made: The motion interference in the flexible barrier system can be effectively avoided by using the proposed structural form, with improvement of sliding movement and buffer mechanism.

(1) The deflection-control-based flexible rockfall barrier system has no clear "braking effect" when it is impacted by the rockfall, which reduces the possibility of damage and improves the buffer performance of the system.

(2) The working force of the energy dissipating devices is a negative correlation with the elongation of the system. However, when the working force is too large, the system deflection does not relate to it. The parametric study on the energy dissipating devices provides a practical solution for the optimal design of buffer performance of flexible barrier system.

Based on the proposed $F-S$ correlation curve, a hierarchical design standard related to the requirements of performance object can be established by controlling the energy dissipating devices on the support ropes. However, the hierarchical design of performance requires a statistical analysis with large amount of full-scale tests and numerical simulation, which needs more research work in the future.

\section{ACKNOWLEDGMENTS}

The authors are grateful for financial support from the National Natural Science Foundation of China under Grant No. 51678504 and No. 51408498, Department of Science and Technology of Sichuan Province under Grant No. 2018JY0029, Open Fund of National Engineering Laboratory 
for Bridge Structure Safety Technology under Grant No.310821151102, and the Fund of State Key Laboratory of Geohazard Prevention and Geoenvironment Protection under Grant No.SKLGP2016K013. The last author is grateful for financial support the Innovation and Technology Fund of the Hong Kong SAR Government for the project "Development of an Energy Absorbing Device for Flexible Rock-Fall Barriers (ITS/059/16FP)”.

\section{REFERENCES}

[1] Peila D, Pelizza S, Sassudelli F. "Evaluation of Behaviour of Rockfall Restraining Nets by Full Scale Tests". Journal of Rock Mechanics \& Rock Engineering, 1998, Vol. 31, No. 1, pp. $1-24$.

[2] Escallón J P, Boetticher V, Wendeler C, et al. "Mechanics of chain-link wire nets with loose connections". Engineering Structures, 2015, Vol. 101, pp. 68-87.

[3] Zhao Shichun, Yu Zhixiang, Zhao Lei, et al. "Damage mechanism of rockfall barriers under strong impact loading”, Journal of Engineering Mechanics, 2016, Vol. 33, No. 10, pp. 24-34.

[4] Zhao Shichun, Yu Zhixiang, Wei Tao, et al. "Test study of force mechanism and numerical calculation of safety netting system”. Journal of China Civil Engineering Journal, 2013, Vol.46, No. 5, pp. 122-128.

[5] Gottardi G, Govoni L. "Full-scale Modelling of Falling Rock Protection Barriers". Journal of Rock Mechanics \& Rock Engineering, 2010, Vol. 43, No. 3, pp. 261-274.

[6] Escallón J P, Wendeler C, Chatzi E, et al. "Parameter identification of rockfall protection barrier components through an inverse formulation". Journal of Engineering Structures, 2014, Vol. 77, pp. 1-16.

[7] Grassl H, Bartelt P A, Volkwein A, et al. "Experimental and numerical modeling of highly flexible rockfall protection barriers" Proceedings of 12th Panamerican Conference on Soil Mechanics and Geotechnical Engineering, Cambridge, Massachusetts, USA, 2003, Vol. 2589-2594.

[8] Qi Xin. “The Mechanics Performance of Passive Flexible Protection Structure”. Southwest Jiaotong University, 2014.

[9] Kwan J S H,Chan S L, Cheuk J C Y, et al. "A case study on an open hillside landslide impacting on a flexible rockfall barrier at Jordan Valley", Journal of Hong Kong. Landslides, 2014, Vol. 11, No. 6, pp. 1-14.

[10] Gentilini C, Govoni L, Miranda S D, et al. "Three-dimensional numerical modelling of falling rock protection barriers". Journal of Computers \& Geotechnics, 2012, Vol. 44, No. 44, pp. 58-72.

[11] Bertrand D, Trad A, Limam A, et al. "Full-Scale Dynamic Analysis of an Innovative Rockfall Fence Under Impact Using the Discrete Element Method: from the Local Scale to the Structure Scale”. Journal of Rock Mechanics \& Rock Engineering, 2012, Vol. 45, No. 5, pp. 885-900.

[12] Volkwein A. "Numerical modelling of flexible rockfall protection systems". Journal of American Society of Civil Engineers, 2013, Vol. 11, No. 179, pp. 1-11.

[13] Moon T, Oh J, Mun B. "Practical design of rockfall catchfence at urban area from a numerical analysis approach". Journal of Engineering Geology, 2014, Vol. 172, No. 5, pp. 41-56.

[14] Gentilini C, Gottardi G, Govoni L, et al. "Design of falling rock protection barriers using 
numerical models”. Journal of Engineering Structures, 2013, Vol.50, No. 3, pp. 96-106.

[15] Muhunthan, B.,H. Radhakrishnan., "Finite Element Analysis of Hybrid Barrier for Rock Fall Slope Protection", Final Report, Department of Civil and Environmental Engineering, Washington State University, 2007.

[16] Miranda S D, Gentilini C, Gottardi G, et al. "Virtual testing of existing semi-rigid rockfall protection barriers", Journal of Engineering Structures, 2015, Vol. 85, pp. 83-94.

[17] Gentilini C, Ubertini F, Govoni L, et al. "Modelling of falling rock protection barriers", Journal of Physical Modelling in Geotechnics, 2011, Vol. 11, No. 4, pp. 126-137.

[18] Miranda S D, Gentilini C, Gottardi G, et al. "A simple model to simulate the full-scale behaviour of falling rock protection barriers", Physical Modelling in Geotechnics, 2010.

[19] Geobrugg.https://www.geobrugg.com/zh/Rockfall-protection-barriers-RXE-77708, 7859.html.

[20] Livermore software technology corporation (LSTC), LS-DYNA keyword user's manual volume I, 2007.

[21] EOTA. Guideline for European technical approval of falling rock protection kits (ETAG 027), 2012, Brussels.

[22] Castanon-Jano L, Blanco-Fernandez E., "Castro-Fresno D, et al Energy Dissipating Devices in Falling Rock Protection Barriers", Journal of Rock Mechanics \& Rock Engineering, 2017, Vol 50, pp. 1-17.

[23] GB/T 20118-2006, Steel wire ropes for general purpose, Standardization Administration of the People's Republic of China, Beijing, 2006.

[24] Higgins J D, "Recommended procedure for the testing of rockfall barriers", AASHTO Technical Report, Washington, 2003.

[25] Peila D, Ronco C, "Technical Note: Design of rockfall net fences and the new ETAG 027 European guideline", Journal of Natural Hazards and Earth System Sciences, 2009, Vol. 9, No. 4, pp. 1291-1298.

[26] Muhunthan B, Shu S, Sasiharan N, "Analysis and design of wire mesh/cable net slope protection", Washington State Transportation Center (TRAC) Report, 2005.

[27] Qiao Wentao, An Qi, Zhao Mingshan, et al., "Experimental study on the fundamental mechanical features of cable-supported ribbed beam composite slab structure", Advanced Steel Construction, 2017, Vol. 13, No. 2, pp. 96-116.

[28] Guo Jiamin, Yuan Xingfei, Xiong Zhixin, et al., "Force finding of suspended-domes using back propagation (BP) algorithm", Advanced Steel Construction, 2016, Vol. 12, No. 1, pp. 17-31.

[29] Luo Bin, Guo Zhengxing, Chen Xiangnan, et al., "Static equilibrium form-finding analysis of cable-strut system based on nonlinear dynamic finite element method", Advanced Steel Construction, 2015, Vol. 11, No. 4, pp. 452-468. 